\title{
The white-light humidified optical particle spectrometer (WHOPS) - a novel airborne system to characterize aerosol hygroscopicity
}

\author{
B. Rosati ${ }^{1}$, G. Wehrle ${ }^{1}$, M. Gysel ${ }^{1}$, P. Zieger ${ }^{1, *}$, U. Baltensperger ${ }^{1}$, and E. Weingartner ${ }^{1,{ }^{* *}}$ \\ ${ }^{1}$ Laboratory of Atmospheric Chemistry, Paul Scherrer Institute (PSI), 5232 Villigen, Switzerland \\ *now at: Department of Applied Environmental Science, Stockholm University, \\ 10691 Stockholm, Sweden \\ ** now at: Institute for Aerosol and Sensor Technology, University of Applied Science \\ Northwestern Switzerland, 5210 Windisch, Switzerland
}

Correspondence to: E. Weingartner (ernest.weingartner@fhnw.ch)

Received: 12 June 2014 - Published in Atmos. Meas. Tech. Discuss.: 21 July 2014

Revised: 29 January 2015 - Accepted: 30 January 2015 - Published: 25 February 2015

\begin{abstract}
Aerosol particles experience hygroscopic growth at enhanced relative humidity (RH), which leads to changes in their optical properties. We developed the white-light humidified optical particle spectrometer (WHOPS), a new instrument to investigate the particles' hygroscopic growth. Here we present a detailed technical description and characterization of the WHOPS in laboratory and field experiments. The WHOPS consists of a differential mobility analyzer, a humidifier/bypass and a white-light aerosol spectrometer (WELAS) connected in series to provide fast measurements of particle hygroscopicity at subsaturated RH and optical properties on airborne platforms. The WELAS employs a white-light source to minimize ambiguities in the optical particle sizing. In contrast to other hygroscopicity instruments, the WHOPS retrieves information of relatively large particles (i.e., diameter $D>280 \mathrm{~nm}$ ), therefore investigating the more optically relevant size ranges.

The effective index of refraction of the dry particles is retrieved from the optical diameter measured for size-selected aerosol samples with a well-defined dry mobility diameter. The data analysis approach for the optical sizing and retrieval of the index of refraction was extensively tested in laboratory experiments with polystyrene latex size standards and ammonium sulfate particles of different diameters. The hygroscopic growth factor (GF) distribution and aerosol mixing state is inferred from the optical size distribution measured for the size-selected and humidified aerosol sample. Laboratory experiments with pure ammonium sulfate particles
\end{abstract}

revealed good agreement with Köhler theory (mean bias of $\sim 3 \%$ and maximal deviation of $8 \%$ for GFs at $\mathrm{RH}=95 \%$ ).

During first airborne measurements in the Netherlands, GFs (mean value of the GF distribution) at $\mathrm{RH}=95 \%$ between 1.79 and 2.43 with a median of 2.02 were observed for particles with a dry diameter of $500 \mathrm{~nm}$. This corresponds to hygroscopicity parameters $(\kappa)$ between 0.25 and 0.75 with a median of 0.38 . The GF distributions indicate externally mixed particles covering the whole range of GFs between $\sim 1.0$ and 3.0. On average, $\sim 74 \%$ of the $500 \mathrm{~nm}$ particles had GFs $>1.5, \sim 15 \%$ had GF $<1.1$ and the remaining $\sim 11 \%$ showed values of $1.1<\mathrm{GF}<1.5$. The more hygroscopic mode sometimes peaked at GF $>2$, indicating influence of sea-salt particles, consistent with previous groundbased particle hygroscopicity measurements in this area. The mean dry effective index of refraction for $500 \mathrm{~nm}$ particles was found to be rather constant with a value of $1.42 \pm 0.04$ (mean $\pm 1 \mathrm{SD}$ ).

\section{Introduction}

Atmospheric aerosols affect the Earth's radiative budget directly and indirectly. The scattering or absorption of incident sunlight by aerosol particles is called the direct aerosolradiation effect. The aerosol optical properties depend on various factors like chemical composition, size and the ability of the particles to take up water. If particles are hygroscopic, their size and index of refraction and hence their op- 
tical properties change with changing relative humidity (e.g., Zieger et al., 2013). The knowledge of their hygroscopic properties and mixing state is central for climate forcing calculations and for the validation of remote-sensing measurements with in situ ones. This is of particular importance if the chemical composition and thus the hygroscopicity changes with altitude, e.g., due to temperature-dependent ammonium nitrate partitioning (Morgan et al., 2010). Therefore, vertical profiles of aerosol properties are essential to enable more accurate model calculations and improve remote-sensing retrieval validation.

The hygroscopic growth of the particles can be described by the growth factor (GF), which is defined as the particle diameter $D_{\text {wet }}$ at a certain relative humidity $(\mathrm{RH})$ divided by the dry diameter $D_{\text {dry }}$ :

$\mathrm{GF}(\mathrm{RH})=\frac{D_{\text {wet }}(\mathrm{RH})}{D_{\text {dry }}}$.

For a given chemical composition, the GF is dependent on $\mathrm{RH}$ and on the particle size (Kelvin effect). Therefore, to compare to other hygroscopicity measurements and to literature data, the hygroscopicity parameter $\kappa$ is often used, which can be obtained from the GF and water activity $\left(a_{\mathrm{W}}\right)$ using $\kappa-$ Köhler theory described by Petters and Kreidenweis (2007):

$\kappa=\frac{\left(\mathrm{GF}(\mathrm{RH})^{3}-1\right) \cdot\left(1-a_{\mathrm{w}}\right)}{a_{\mathrm{w}}}$.

The water activity can be inferred from the RH and equilibrium droplet diameter $\left(D_{\text {wet }}\right)$ :

$a_{\mathrm{w}}=\frac{\mathrm{RH}}{\exp \left(\frac{4 \sigma_{\mathrm{s}} M_{\mathrm{w}}}{R T \rho_{\mathrm{w}} D_{\mathrm{wet}}}\right)}$,

where $\sigma_{\mathrm{s}}$ is the surface tension of the solution, $R$ the ideal gas constant, $T$ the absolute temperature, $\rho_{\mathrm{w}}$ the density of water and $M_{\mathrm{w}}$ the molecular mass of water. The $\kappa$ parameter has the advantage that it is for the most part determined by the chemical composition of a particle, while it is independent of particle size and only weakly dependent on $\mathrm{RH}$ (at least within limited variations of RH). It allows a direct comparison of measurements made at different dry sizes and RH.

The need to quantify the hygroscopicity of aerosol particles led to the development of several instruments including the hygroscopicity tandem differential mobility analyzer (HTDMA; e.g., Liu et al., 1978; Swietlicki et al., 2008). It measures dry and humidified mobility diameters whereby the $\mathrm{RH}$ of the humidified differential mobility analyzer (DMA) can be varied, making it possible to record humidograms. Even if this instrument provides high-precision measurements of GFs and hygroscopic mixing state of the aerosol, the measurement duration for one measurement amounts to several minutes, which makes it rather unsuited for airborne studies. Besides this, the maximal dry mobility diameter that can be detected is approximately $250 \mathrm{~nm}$. The diameter size range of the standard HTDMA is therefore limited to small particles and might miss hygroscopic features of larger particles (e.g., sea salt; Zieger et al., 2011), which are also important for aerosol light scattering.

In contrast, the differential aerosol sizing and hygroscopicity spectrometer probe (DASH-SP; Sorooshian et al., 2008) was developed specifically to provide a fast measurement of the GF. It can measure at different RHs simultaneously and the maximum dry diameter it can detect accurately is $450 \mathrm{~nm}$. The measurement principle is based on a combination of a DMA and optical particle size spectrometer (OPSS), which has also been utilized in previous techniques such as the LACIS (Leipzig Aerosol Cloud Interaction Simulator; Stratmann et al., 2004; Kiselev et al., 2005). In the DASHSP a specific monodisperse aerosol is selected in the DMA, then exposed to different RHs and finally measured in the OPSS. However, the OPSS uses monochromatic light which can lead to ambiguities for the diameter retrieval.

Another instrument that can be compared to the ones above is the humidified nephelometer (Wet-Neph; e.g., FierzSchmidhauser et al., 2010) which measures the aerosol light scattering coefficient at dry and elevated RH and allows retrieval of the light scattering enhancement factor. However, in the usual setup, no size-specific or mixing-state information can be retrieved.

In this paper, we describe a novel instrument that has specifically been developed for airborne measurements of aerosol particles in the optically relevant size range. The white-light humidified optical particle spectrometer (WHOPS) uses a DMA-OPSS setup to allow the detection of larger aerosol sizes. A white-light aerosol spectrometer (WELAS) was chosen for the optical measurements since it uses a white-light source to illuminate the particles, which in turn allows for an unambiguous relation between the light intensity scattered by a particle and its size. Another advantage is the simultaneous measurement of all sizes in the detectable range of approximately 280 to $10 \mu \mathrm{m}$ that allows a faster measurement.

\section{Method}

\subsection{Setup of the PSI-Zeppelin rack}

The instrument was specifically developed for airborne measurements on board an airship (Zeppelin NT). The compact rack contains the WHOPS, another WELAS and an aethalometer, see Fig. 1.

To collect the aerosol an inlet was built for isokinetic sampling at an average flight velocity of $50 \mathrm{~km} \mathrm{~h}^{-1}$. Then, the flow is split in three ways:

$5 \mathrm{Lmin}^{-1}$ are directed to a WELAS 2300 (Palas $\mathrm{GmbH}$, Karlsruhe, Germany) sensor to measure the polydisperse size distribution of the ambient aerosol (labeled as WELAS1 in 


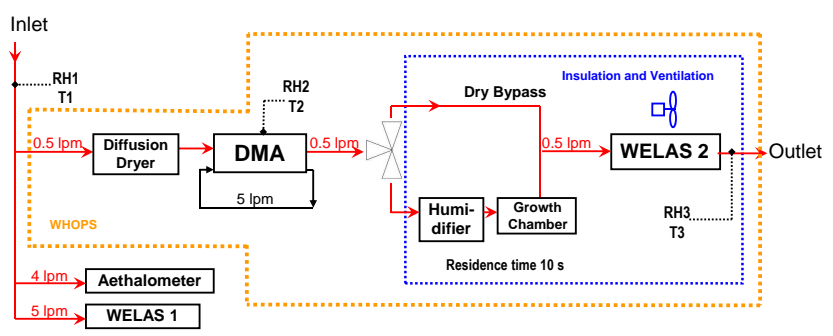

Figure 1. Setup of the PSI-Zeppelin rack containing the WHOPS along with an aethalometer and the WELAS1 sharing the sampling line in configuration for the airborne measurements. The positions of the RH and $T$ sensors are shown (RH1, T1, etc).

Fig. 1). This sensor uses an intense source of white light (Osram XBO-75 xenon short arc lamp) to illuminate a certain sensing volume (approximately $224 \mu \mathrm{m} \times 224 \mu \mathrm{m} \times 140 \mu \mathrm{m}$ ) with a 3-D T-shape to minimize "border-zone" errors, i.e., to ensure a uniform light intensity across the whole sensing volume (see Heim et al., 2008, for more details). Optical lenses collect the scattered light between $78^{\circ}$ and $102^{\circ}$ with respect to the incident beam and direct it to a photomultiplier tube (PMT) which detects the partial scattering cross section of the particles for this solid angle. The so-called "PROMO 3000 box" contains the PMT and lamp which are connected to the sensor via optical fibers to minimize heat input from the lamp and thus a temperature increase. Since each signal pulse height recorded by the PMT can be related to a corresponding optical particle size (see Sect. 2.2.1), the particle number size distribution can be retrieved. The diameters that can be detected range from approximately $280 \mathrm{~nm}$ to $10 \mu \mathrm{m}$ in polystyrene latex (PSL) equivalent particle diameters, though with decreasing detection efficiency for the smallest sizes. The lower limit is given by the minimum detection threshold of the PMT, while the upper limit is reached above saturation of the detection electronics.

The WHOPS uses a combined setup of a DMA and another WELAS 2300 sensor (labeled as WELAS2 in Fig. 1) connected in series. This WELAS2 was modified to operate at a reduced sample flow rate of $0.5 \mathrm{~L} \mathrm{~min}^{-1}$ in order to be able to operate the DMA with sample and sheath air flow rates of 0.5 and $5.0 \mathrm{~L} \mathrm{~min}^{-1}$, respectively, without adding dilution air between DMA and WELAS2. In order to increase the detection probability of the particles, a nozzle was implemented by the manufacturer in the WELAS2 inlet, guiding the flow directly towards the measurement volume.

In the WHOPS the air passes a silica gel dryer and reaches a DMA, where particles with a certain mobility diameter are selected. In the next step these monodisperse particles can be measured either under dry or wet conditions. The WHOPS is operated in the wet mode to study the hygroscopic behavior: the dried and size-selected particles pass through a custom-built humidifier before they enter a residence chamber. There, the particles are exposed to high RH for approxi- mately $20 \mathrm{~s}$. This residence time should be sufficient for most aerosol particles to reach their equilibrium growth factor, including complete deliquescence (Sjogren et al., 2007). The WELAS2 is then used to determine the resulting equilibrium diameters of the grown particles at elevated $\mathrm{RH}$, typically around $95 \%$. To maintain a constant RH, the humidifier and the optical sensor are situated in an insulated box with a fan to ensure a well-stirred air circulation and therefore a homogeneous temperature. The measurement of the RH is crucial for a correct interpretation of the observed GF. Figure 1 shows that $3 \mathrm{RH}$ and temperature $(T)$ measurements are included in the setup. We use HC-S probes (hygroclip-S; Rotronic AG, Bassersdorf, Switzerland) which monitor RH changes with a precision of $\pm 0.8 \%$. However, extensive laboratory tests showed that at changing conditions at high RH (above $90 \% \mathrm{RH}$ ), the sensors and the tubes need an equilibrium time of approximately $3-5 \mathrm{~min}$. Therefore, all $\mathrm{RH}$ measurements under transient conditions were corrected for equilibration time effects. The accuracy of the corrected RH measurements is estimated to be $\sim \pm 2 \%$. The good agreement between theoretical and measured hygroscopic growth factors of ammonium sulfate results presented in Sect. 3.1.4 supports this assumption. To ensure this accuracy and precision, the sensors were regularly calibrated using saturated salt solutions with different deliquescence RH.

The WHOPS is operated in the dry mode to investigate the optical properties of the dry aerosol: the particles selected by the DMA are led through a bypass directly into the WELAS2. In this way it is possible to compare the dry mobility diameter of the size-selected particles with their partial scattering cross section. This relationship is then used to retrieve optical properties of the dry aerosol (i.e., the dry effective index of refraction; see Sect. 2.2.2). However, the WELAS 1 and 2 are connected to the same PMT and lamp in the PROMO box, which further means that the measurements can only be performed alternately and not simultaneously. Additionally, the pressure change at different altitudes has to be taken into account for the actual selected diameters in the DMA.

Another $4 \mathrm{~L} \mathrm{~min}^{-1}$ of the sample flow reaches the portable aethalometer (AE42, MAGEE Scientific; Berkeley, USA), which contains LEDs of seven different wavelengths between $\lambda=370$ and $950 \mathrm{~nm}$ to measure the light absorption coefficient and retrieve the equivalent black carbon mass concentration. The flow rate is regulated by a mass flow controller; therefore corrections for pressure changes were performed.

\subsection{WHOPS characterization}

\subsubsection{Conversion of light scattering pulse height to optical diameters}

The state-of-the-art approach for particle sizing with an optical particle size spectrometer consists of two steps: first, 
the instrument calibration factor relating the pulse height (voltage) to the scattering cross section (particle property) is determined with an empirical calibration using particles of known scattering cross section. Second, the relationship between scattering cross section and particle size is obtained from Mie theory (Mie, 1909; Bohren and Huffman, 2007). The combination of the instrument calibration factor with the Mie curves provides the relationship between pulse height and corresponding optical particle size. In order to obtain a meaningful optical diameter, e.g., equal to the geometric diameter for homogeneous spherical particles, it is crucial to consider all relevant properties of the light source, the detector geometry and the observed particles in the Mie calculations.

The pulse height recorded as a raw voltage $\left(V_{\text {raw }}\right)$ by the PMT situated in the "PROMO 3000 box", which is a measure for the scattered light intensity, is directly proportional to the light intensity of the xenon lamp ( $\left.I_{\mathrm{xenon}}\right)$ and to the particles' partial scattering cross section for the solid angle covered by the detector optics ( $\bar{\sigma}$; from now on referred to as "scattering cross section"):

$V_{\text {raw }} \propto \bar{\sigma} I_{\text {xenon }}$.

In order to calculate instrument-specific Mie curves (i.e., scattering cross section $\bar{\sigma}$ as a function of the particle diameter), the theoretical scattering cross section $(\sigma(\lambda, D, m, \Omega))$, which depends on the wavelength $(\lambda)$, diameter $(D)$, refractive index $(m)$ and the solid angle $(\Omega)$ covered by the light collection optics of the WELAS, has to be averaged over all wavelengths weighted with the relevant light-intensity spectrum, $\frac{\mathrm{d} I_{\text {Mie }}(\lambda)}{\mathrm{d} \lambda}$ :

$\bar{\sigma}(D, m, \Omega)=\frac{\int \sigma(\lambda, D, m, \Omega) \frac{\mathrm{d} I_{\text {Mie }}(\lambda)}{\mathrm{d} \lambda} \mathrm{d} \lambda}{\int \frac{\mathrm{d} I_{\text {Mie }}(\lambda)}{\mathrm{d} \lambda} \mathrm{d} \lambda}$.

The relevant light intensity spectrum differs from the spectrum of the xenon lamp, $\frac{\mathrm{d} I \text { Xenon }(\lambda)}{\mathrm{d} \lambda}$, as the light transmission and detection efficiency of the optical components and detector depend on the wavelength. They are related through

$$
\begin{gathered}
\frac{\mathrm{d} I_{\text {Mie }}(\lambda)}{\mathrm{d} \lambda}=\frac{\mathrm{d} I_{\text {Xenon }}(\lambda)}{\mathrm{d} \lambda} f_{\text {fibre, lamp }}(\lambda) f_{\text {lens }}(\lambda) f_{\text {fibre, } \operatorname{PMT}}(\lambda) \\
f_{\mathrm{PMT}}(\lambda) \approx \frac{\mathrm{d} I_{\text {Xenon }}(\lambda)}{\mathrm{d} \lambda} f_{\text {lens }}(\lambda) f_{\mathrm{PMT}}(\lambda)
\end{gathered}
$$

where the factors $f_{x}(\lambda)$ describe the relative wavelength dependence for the key components, $f_{\text {fibre, lamp }}(\lambda)$ is the light transmission efficiency between the xenon lamp and the detection volume (assumed to be constant, i.e., $f_{\text {fibre, lamp }}(\lambda) \equiv$ $1), f_{\text {lens }}(\lambda)$ is the light transmission efficiency of the lens collecting the scattered light, $f_{\text {fibre,PMT }}(\lambda)$ is the light transmission efficiency between the lens and the PMT (assumed to be constant, i.e., $\left.f_{\text {fibre, } \mathrm{PMT}}(\lambda) \equiv 1\right)$ and $f_{\mathrm{PMT}}(\lambda)$ is light detection efficiency of the bialkali PMT. Note that the normalization of any $f_{x}(\lambda)$ can randomly be chosen, as any

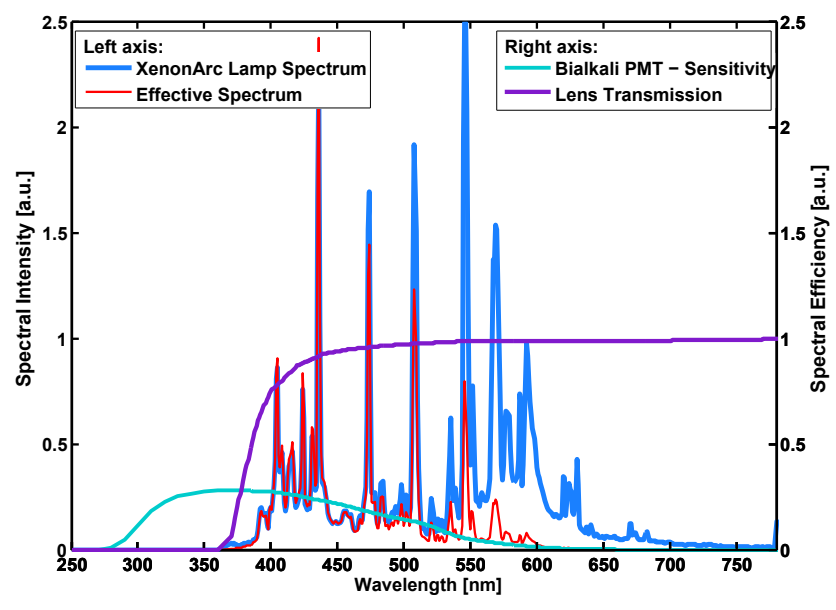

Figure 2. The effective light spectrum (red line; a.u.), which is relevant for scattering cross section calculations, is obtained by multiplication of the xenon arc lamp light spectrum (blue line; a.u.) with the wavelength-dependent lens transmission (WELAS light collection optics; purple line; absolute values) and bialkali PMT sensitivity (turquoise line; a.u.) and an arbitrary constant scaling factor (chosen to get equal values of the red and blue lines at $450 \mathrm{~nm}$ wavelength).

changes of the normalization factors are canceled out in Eq. (5). Figure 2 illustrates all important spectra and efficiency curves for the WELAS. The PMT efficiency $\left(f_{\mathrm{PMT}}\right.$; turquoise curve in Fig. 2), which gradually decreases from its maximum at wavelengths below $400 \mathrm{~nm}$ down to an efficiency of $0 \%$ at $\sim 600 \mathrm{~nm}$, has a strongly distorting effect on the relevant spectrum $\frac{\mathrm{d} I_{\text {Mie }}(\lambda)}{\mathrm{d} \lambda}$ by reducing the contribution by larger wavelengths. The lens transmission $\left(f_{\text {lens }}\right.$; purple curve in Fig. 2), which is unity for the dominant fraction of the lamp spectrum while it only drops at shorter wavelengths $(<400 \mathrm{~nm})$, has a minor influence on $\frac{\mathrm{d} I_{\text {Mie }}(\lambda)}{\mathrm{d} \lambda}$. A DMA-selected aerosol sample has a finite width rather than being perfectly monodisperse. Thus Eq. (6) should also be averaged over the size distribution of the quasi-monodisperse sample. However, we simply used the nominal dry diameter $\left(D_{\text {dry,meas }}\right)$ for the Mie calculations. This does not introduce significant errors for polychromatic light, as averaging over wavelength or size has similar effects.

The raw voltage recorded for particles with a certain scattering cross section can potentially drift over time due to drifts of the light intensity of the xenon lamp $\left(I_{\text {xenon }}\right)$, PMT sensitivity, detector electronics, optics contamination, etc. Such temporal drifts of the WELAS sensitivity are accounted for by correcting the measured raw voltages with a timedependent voltage calibration factor $C_{\mathrm{V}}$ :

$V_{\text {cal }}=C_{\mathrm{V}}(t) V_{\text {raw }}$.

This approach, which follows the manufacturer's instructions, ensures that a certain calibrated voltage signal $\left(V_{\text {cal }}\right)$ always corresponds to the same scattering cross section. In 
practice, the software calculates the voltage calibration factor internally by relating the raw voltage signal measured for quasi-monodisperse Caldust 1100 (calibration dust with a diameter of $1.1 \mu \mathrm{m}$ and an index of refraction of 1.43 , which relates to a diameter of $850 \mathrm{~nm}$ for an index of refraction of 1.59; provided by the manufacturer) at a certain time $t$ (user calibration) to the raw signal measured at a reference time $t_{0}$ (initial factory calibration):

$C_{\mathrm{V}}(t)=\frac{V_{\text {raw }}\left(\text { Caldust }, t_{0}\right)}{V_{\text {raw }}(\text { Caldust }, t)}$.

An absolute calibration factor $\left(C_{\sigma}\right)$ for scattering cross section measurements is obtained by recording the calibrated voltage signal for PSL spheres with a certified diameter and relating it to results from Mie calculations:

$C_{\sigma}=\frac{\bar{\sigma}(\mathrm{PSL})}{V_{\mathrm{cal}}(\mathrm{PSL})}$.

$\bar{\sigma}$ (PSL) of the PSL spheres $(m=1.59+0 i)$ is calculated using Eq. (5) to account for the instrument specific intensity spectrum. In principle, the calibration factor $C_{\sigma}$ is expected to be independent of the PSL diameter used to determine it. However, tests with different PSL sizes revealed a weak dependence of $C_{\sigma}$ on PSL size (see Sect. 3.1.2). Thus, a calibration function $C_{\sigma}\left(V_{\text {cal }}\right)$, rather than a simple calibration constant, is used to infer absolute scattering cross section values from the calibrated voltages measured for any sample aerosol according to the following equation:

$\bar{\sigma}\left(V_{\text {cal }}\right)=C_{\sigma}\left(V_{\text {cal }}.\right) V_{\text {cal }}$

Absolute scattering cross section values, determined with Eq. (10) for any kind of aerosol sample, form the basis for meaningful optical sizing. The relationship between scattering cross section and corresponding geometric particle diameters can be calculated with Mie theory (and Eq. 5 to account for the instrument-specific intensity spectrum) if the particles are spherical with a known refractive index. If the particles are non-spherical or if the refractive index is unknown, then it is only possible to infer an "equivalent optical diameter" representing the size of a sphere with a certain refractive index that has the same scattering cross section as the particle under investigation. It is further detailed in Sect. 3.1.2 how meaningful optical sizes are inferred from WELAS measurements of the dried and humidified aerosol samples probed in the WHOPS setup.

The real part of the index of refraction $m$ of PSL shows a weak wavelength dependence, decreasing from 1.617 at $\lambda=400 \mathrm{~nm}$ to 1.572 at $1000 \mathrm{~nm}$ (Kasarova et al., 2007; Ma et al., 2003). Furthermore, a non-zero imaginary part was reported from measurements at a shorter wavelength of about $260 \mathrm{~nm}$ (Gaigalas et al., 2013). In this study, a constant index of refraction of $1.59+0 i$ across the whole relevant spectrum is used in the Mie calculations for PSL spheres. The weak wavelength dependence and the marginal imaginary part are ignored, as they only have a negligible effect.

A mean index of refraction $m$ of dry ammonium sulfate crystals is reported in the literature as $1.53 \pm 0.01$ (real part; Toon et al., 1976) at wavelengths between 300 and $800 \mathrm{~nm}$. This value was used in the Mie calculations for the optical sizing of pure ammonium sulfate aerosols in laboratory experiments. The assumptions made for $m$ in the analysis of ambient WHOPS measurements are discussed in detail in Sects. 2.2.2 and 3.1.3.

Unfortunately, the WELAS instrument does not report the raw voltages and calibrated voltages corresponding to the reported optical diameter values. However, the calibrated voltages can be inferred from the optical diameters using the instrument's preset PSL-based calibration curve ( $D_{\mathrm{PSL}}$ vs. $V_{\text {cal }}$; provided by the manufacturer). In a second step the raw voltages can be reconstructed from the calibrated voltages using Eq. (7) and the voltage calibration $C_{\mathrm{V}}$ noted during the last user calibration (and stored in the instrument software).

\subsubsection{Retrieval of index of refraction and hygroscopic growth factor}

Using a lookup table is useful to avoid iterative approaches and repeated computationally expensive Mie calculations for the retrieval of the index of refraction $\left(m_{\mathrm{dry}}\right)$ of the dry particles from the dry-mode WHOPS measurement and of the hygroscopic growth factor from the wet-mode WHOPS measurement. Figure 3 presents the algorithms used to infer these quantities. A similar approach was described in previous articles like in Flores et al. (2009) for WELAS measurements or in Hand and Kreidenweis (2002).

Box 1 in Fig. 3 describes how the lookup table is generated in a preparation step for repeated use in the data analysis steps 2 and 3. Starting from a given $D_{\mathrm{dry}}$, GF, and index of refraction of the dry particle ( $\left.m_{\mathrm{dry}}\right)$, the corresponding solution droplet diameter $\left(D_{\text {wet }}\right)$ and the index of refraction of the solution droplet $\left(m_{\mathrm{mix}}\right)$ are calculated. The mean of $m_{\mathrm{dry}}$ and the index of refraction of pure water $\left(m_{\mathrm{H}_{2} \mathrm{O}}=1.333\right)$, weighted with their respective volumes, is used to infer $m_{\text {mix }}$. Mie theory for homogeneous spherical particles (see also Sect. 2.2.1) is then applied to calculate the scattering cross section $\left(\sigma_{\text {wet }}\left(D_{\text {wet }}, m_{\text {mix }}\right)\right)$ of this solution droplet. The complete lookup table is obtained by calculating $\sigma_{\text {wet }}$ with the above approach for the relevant ranges of the free parameters GF, $D_{\text {dry }}$ and $m_{\text {dry }}$.

The homogeneous sphere model used to generate the lookup table, which accounts for the change in the refractive index caused by the absorption of water, is considered to be the most suitable choice for the analysis of the WHOPS measurements. A coated sphere model is expected to be more accurate for particles that contain insoluble material. However, in the size range between 300 and $500 \mathrm{~nm}$ dry diameter, the insoluble volume fraction is expected to be very small in the majority of the particles. Furthermore, the insoluble vol- 


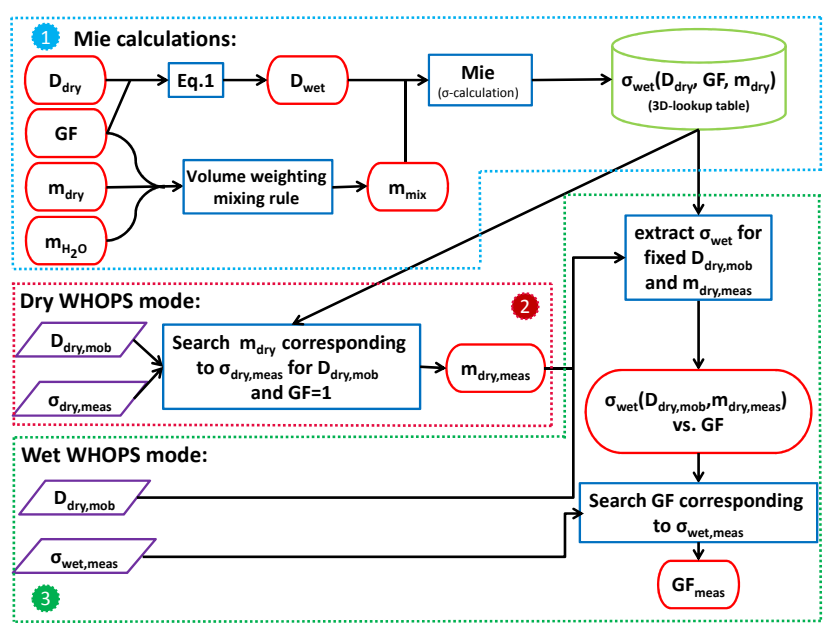

Figure 3. Schematic of the approach applied to analyze the WHOPS measurements, indicated with the violet rhombi, which can be divided into three main steps: first (blue dashed box), a 3-D lookup table containing $\sigma_{\text {wet }}$ as a function of $D_{\text {dry }}, m_{\text {dry }}$ and GF is prepared using Mie theory. Second (red dashed box), the results from the dry-mode WHOPS measurements are used to infer the effective index of refraction $\left(m_{\text {dry, meas }}\right)$ of the dry particles. Third (green dashed box), the scattering cross sections $\sigma_{\text {wet, meas }}$ of the humidified particles measured in the wet WHOPS mode are converted to corresponding growth factors ( $\left.\mathrm{GF}_{\text {meas }}\right)$.

ume fraction is neither available on a single particle basis nor can it reliably be derived from the measured scattering cross section of the humidified particle. Sensitivity analyses comparing the homogeneous mixture to the core-shell model revealed that the discrepancies in the retrieved GF are generally less than $10 \%$ for particles with a soluble volume fraction of $>70 \%$. The largest discrepancies ( $\sim 20 \%$ in GF) occur for particles containing a large fraction of insoluble material $(70-90 \%)$ in the range of $1.1<\mathrm{GF}<1.5$.

Operating the WHOPS in the dry bypass mode (see Fig. 1) yields a measurement of the scattering cross section $\left(\sigma_{\text {dry,meas }}\right)$ of dry particles with a well-defined mobility diameter $\left(D_{\mathrm{dry}}\right.$ mob). The data analysis step presented in box 2 of Fig. 3 provides the effective index of refraction $\left(m_{\text {dry }}\right.$, meas $)$ of these dry particles, simply by searching the lookup table (which has a resolution of $\Delta m=0.005$ in the index of refraction) for the $m_{\mathrm{dry}}$ corresponding to $\sigma_{\mathrm{dry}}$, meas for $D_{\mathrm{dry}}$, mob and GF $=1$ (no hygroscopic growth in the dry mode). The qualifier "effective" is used because the true index of refraction might be different due to the following simplifications: the retrieved index of refraction represents a weighted mean with the effective light spectrum from Fig. 2 as a weighting function; the imaginary part of the index of refraction is assumed to be zero and all particles are assumed to be spherical and perfectly internally mixed (equal composition of all individual particles of equal size).

In the wet mode of the WHOPS (see Fig. 1), the WELAS2 measures the scattering cross section distribution of
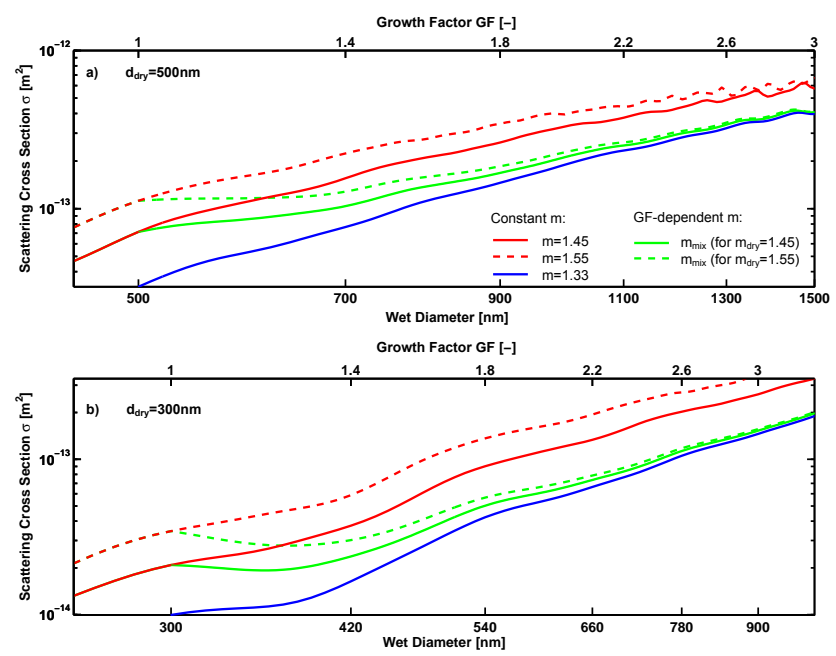

Figure 4. Calculated scattering cross section as a function of particle diameter (hygroscopic growth factor) for solution droplets (green lines) formed on particles with a dry diameter of (a) $500 \mathrm{~nm}$ and (b) $300 \mathrm{~nm}$. A volume weighting mixing rule is used to determine the index of refraction of the solution droplet (see Sect. 2.2.2 and Fig. 3). The Mie curves for pure water droplets $\left(m_{\mathrm{H}_{2} \mathrm{O}}=1.333\right.$; blue lines) and particles with a constant index of refraction, $m_{\text {dry }}=$ 1.45 (solid red lines) and $m_{\text {dry }}=1.55$ (dashed red lines), are also shown as a reference.

the size-selected particles at high RH. The hygroscopic water uptake gradually reduces the index of refraction of the solution droplets with increasing size (GF). The scattering cross section of a wet particle ( $\left.\sigma_{\text {wet, meas }}\right)$ is converted to a meaningful size $\left(\mathrm{GF}_{\text {meas }}\right)$ by using the lookup table and the approach described in box 3 of Fig. 3. First the $\sigma-$ GF relationship is extracted for the dry size selected in the DMA $\left(D_{\mathrm{dry}}, \mathrm{mob}\right)$ and the corresponding effective index of refraction $\left(m_{\text {dry,meas }}\right)$. Finally, the measured GF $\left(\mathrm{GF}_{\text {meas }}\right)$ is obtained by selecting the GF corresponding to the measured $\sigma_{\text {wet, meas }}$ from the extracted $\sigma-\mathrm{GF}$ relationship. This allows the conversion of the scattering cross section axis to the corresponding GF axis and thus the transformation of the measured scattering cross section distribution to a meaningful GF distribution.

The scattering cross section as a function of GF (wet diameter) obtained with the above approach is shown in Fig. 4 (green lines) for dry particle diameters of (a) $500 \mathrm{~nm}$ and (b) $300 \mathrm{~nm}$. The Mie curve for pure water droplets $\left(m_{\mathrm{H}_{2} \mathrm{O}}=\right.$ 1.333; blue lines) and particles with a constant index of refraction of $m_{\mathrm{dry}}=1.45$ (red solid line) and $m_{\mathrm{dry}}=1.55$ (red dashed line) are also shown as a reference. The red and blue lines illustrate that the scattering cross section increases with increasing particle size at a constant index of refraction. Hygroscopic growth results in an increase of the particle size and a concurrent decrease of the index of refraction. Thus the green curve, which starts off at the level of the red curve for the initially dry particle, gradually approaches the blue curve 
with increasing GF. First focusing on particles with a dry diameter of $D_{\text {dry, opt }}=500 \mathrm{~nm}$ (panel a), it can be seen that for $m_{\text {dry }}=1.45$ the size effect dominates over the counteracting effect from the change of the index of refraction, thus resulting in a strictly monotonically increasing relationship between $\sigma_{\text {wet, meas }}$ and the GF of the solution droplet (green solid line). This makes unambiguous assignment of a GF to a measured (wet WHOPS mode) $\sigma_{\text {wet, meas }}$ of a solution droplet possible. However, this is not true at droplet diameters above $1400 \mathrm{~nm}$, which corresponds to GF $>2.8$ for $500 \mathrm{~nm}$ particles, where the Mie wiggles in the green line cause small ambiguities that increase the measurement uncertainty in this range (see Sect. 3.1.2). For $500 \mathrm{~nm}$ particles with a higher index of refraction $\left(m_{\mathrm{dry}}=1.55\right)$, the reduction of the index of refraction with water uptake becomes stronger and the Mie curve (green dashed line in Fig. 4a) becomes ambiguous for the range $1<\mathrm{GF}<1.4$. However, we did not observe $m_{\text {dry }}$ values as high as 1.55 during our atmospheric measurements.

Ambiguities in the $\sigma-\mathrm{GF}$ relationship are a major limitation for the optical sizing of solution droplets with a dry size of $D_{\text {dry, opt }}=300 \mathrm{~nm}$ (Fig. $4 \mathrm{~b}$ ): here, the scattering cross section of the growing particles (green lines) decreases with initial water uptake, has a local minimum at a droplet size of $\sim 360-390 \mathrm{~nm}$, and reaches the initial values at droplet diameters of $\sim 400-450 \mathrm{~nm}$ before increasing strictly monotonically at further water uptake. This results in an ambiguous relationship between the scattering cross section and GF in the range GF $<1.32-1.5$ for particles with a dry diameter of $300 \mathrm{~nm}$ particles and an index of refraction of $m_{\mathrm{dry}}=1.45$ 1.55. This makes it impossible to distinguish between GFs in this range, when using the WELAS as an optical sizer (see also uncertainty analysis provided in Sects. 3.1.2 through 3.1.4). However, GFs larger than $\sim 1.32-1.5$ can be unambiguously determined. The exact threshold GF depends weakly on the index of refraction of the dry particles.

In conclusion, the measurement of the GF-PDF (GF probability density function) for dry diameters below $\sim 400 \mathrm{~nm}$ using the WHOPS is limited by the ambiguity in the optical sizing, described above, and the sharp drop in counting efficiency (CE) of the WELAS (see Sect. 3.1.1). While the counting efficiency could potentially be improved, resolving the ambiguity issue would require a different light spectrum and/or optical setup.

Figure 4 also demonstrates the crucial importance of using an appropriate index of refraction for the optical sizing of grown particles, in particular the need to account for the effect of absorbed water. For instance a particle with $D_{\text {dry, opt }}=$ $500 \mathrm{~nm}, m_{\text {dry }}=1.45$ and $\mathrm{GF}=1.4$ (i.e., $D_{\text {wet, opt }}=700 \mathrm{~nm}$ ) has a scattering cross section of $9.91 \times 10^{-14} \mathrm{~m}^{2}$ according to theory (see solid green line in Fig. 4a). If a fixed index of refraction of $m_{\mathrm{dry}}=1.45$ or $m=1.333$ (pure water) were used to infer the size of this solution droplet, the resulting diameters would be $580 \mathrm{~nm}$ or $765 \mathrm{~nm}$, respectively, according to the solid red or blue lines, and the corresponding inferred
GFs would be 1.16 or 1.53 . This would be substantially different $(-17 \%$ or $+9 \%)$ from the true value of 1.4.

\subsection{Laboratory measurements}

Aqueous suspensions of PSL size standards (Duke Standards, Thermo Scientific) were diluted with MilliQ water, nebulized, led through a drier and subsequently measured in the WELAS2. PSL experiments were used to infer the scattering cross section calibration function (Eqs. 9 and 10 and Sect. 3.1.2) as well as for comparison with the manufacturer's calibration.

Ammonium sulfate (AS; Fluka Biochemica; purity $>$ $99.5 \%$ ) particles were used to test the optical sizing for atmospherically relevant particles with an index of refraction that differs from that of PSL, to test the method to retrieve the effective index of refraction of a dried monodisperse particle sample and to determine the counting efficiency of the WELAS. For this purpose, an ammonium sulfate and MilliQ water solution was prepared, nebulized, dried and passed through a neutralizer before being fed to a DMA in order to select particles with a well-defined mobility diameter for testing the WELAS.

For monodisperse samples such as PSL spheres or sizeselected AS, the mean value of the measured signal distribution was used as a representative value (ignoring the signals from multiply charged particles in the case of size-selected AS samples).

\subsection{Field measurements}

Within the Pan-European Gas-AeroSOls-climate interaction Study (PEGASOS; pegasos.iceht.forth.gr) a Zeppelin NT was used to explore the planetary boundary layer (for more information see Stull, 1988). The PSI-Zeppelin rack containing the WHOPS, the aethalometer and an extra WELAS was mounted in the airship to investigate properties of secondary organic aerosol. The first campaign took place in the Netherlands, in the region of Rotterdam, in May 2012. Simultaneously, chemical composition and size distributions were recorded by an Aerodyne aerosol mass spectrometer (Rubach, 2013) and a scanning mobility particle sizer (e.g., Wiedensohler et al., 2012), respectively. Besides this, various gas phase measurements (e.g., $\mathrm{NO}_{\mathrm{x}}, \mathrm{CO}, \mathrm{OH}, \mathrm{O}_{3}$ ) together with GPS (global positioning system) and meteorological data were logged.

During the Zeppelin NT flights the measurement cycle per probed particle size was chosen to be $250 \mathrm{~s}$, where $150 \mathrm{~s}$ are used for the wet-mode and $100 \mathrm{~s}$ for the dry-mode WHOPS measurements. The selected dry diameters were $D_{\text {dry }}=300$ and $500 \mathrm{~nm}$. In order to get accurate, effective indices of refraction and mean growth factors, the mean values were calculated from 70 particles on average. According to the sensitivity analysis provided in Gysel et al. (2009), this is sufficient to avoid additional noise from limited counting statis- 
Table 1. List of uncertainties (1 SD) of all relevant measured and derived quantities (given as relative uncertainties if not otherwise stated). The last two columns contain references to more detailed error analysis figures and to the sections containing the detailed discussion.

\begin{tabular}{lccc}
\hline Description & Uncertainty & Section & Figure \\
\hline Accuracy of the RH & $2 \%$ (absolute) & 3.1 .2 & - \\
Accuracy of the scattering cross section & $15 \%$ & 3.1 .2 & 7 \\
Precision of the scattering cross section & $2 \%$ & 3.1 .3 & - \\
Accuracy of the dry optical diameter & $4-22 \%$ & 3.1 .3 & 8 \\
Precision of the dry optical diameter & $0.1-5 \%$ & 3.1 .3 & 8 \\
Uncertainty of the GF from propagated RH accuracy & $12-17 \% *$ & 3.1 .4 & - \\
Ambiguity uncertainty of the GF & $<7 \% ;<40 \% * *$ & 3.1 .4 & 9 \\
Accuracy of the GF & $5-12 \% * * *$ & 3.1 .4 & 9 \\
Precision of the GF & $1-6 \%$ & 3.1 .4 & $11 \mathrm{~b}$ \\
Precision of the index of refraction & $0.04($ absolute) & 3.1 .5 & 10 \\
Accuracy of the mobility diameter & $5 \%$ & 3.1 .5 & - \\
\hline
\end{tabular}

$*$ at $\mathrm{RH}=95 \%$ and for particles with $\kappa$ values between 0.1 and $0.5 ; * *<7 \%$ applies for particles with $\mathrm{D}_{\mathrm{dry}}=300 \mathrm{~nm}$ with $\mathrm{GF}>1.4$ as well as for particles with $\mathrm{D}_{\mathrm{dry}}=500 \mathrm{~nm}$ and any GF; $<40 \%$ applies for particles with $\mathrm{D}_{\mathrm{dry}}=300 \mathrm{~nm}$ and $\mathrm{GF}<1.4$; *** applies for particles with $\mathrm{D}_{\mathrm{dry}}=300 \mathrm{~nm}$ and $\mathrm{GF}>1.4$ as well as for particles with $\mathrm{D}_{\text {dry }}=500 \mathrm{~nm}$ and $\mathrm{GF}<3$; larger uncertainties apply for particles with GFs outside the indicated GF ranges.

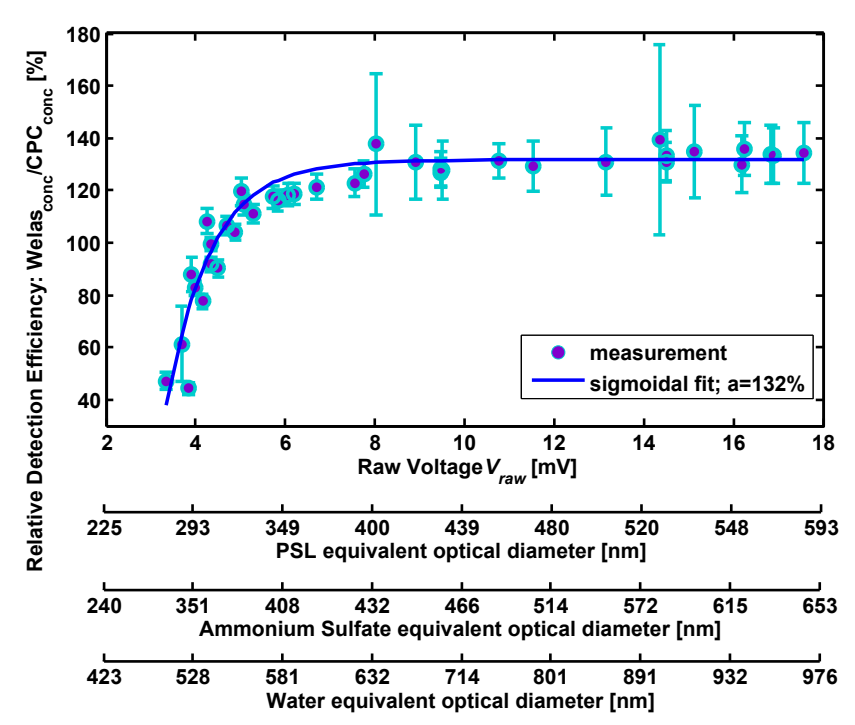

Figure 5. Counting efficiency for size-selected ammonium sulfate particles retrieved by dividing the WELAS number concentration measurement by the corresponding value measured by the CPC. The primary abscissa is the measured raw pulse height $\left(V_{\text {raw }}\right)$. The additional abscissa scales representing the PSL equivalent, ammonium sulfate and water equivalent optical diameters are calculated from $V_{\text {raw }}$ using the mean WELAS calibration value $C_{\mathrm{V}}=2.23$. The value $a$ depicts the plateau value of the sigmoidal fit.

tics. The polydisperse size distribution was recorded for $50 \mathrm{~s}$. Equivalent BC concentrations were logged with a time resolution of $2 \mathrm{~min}$.

\section{Results and discussion}

\subsection{Characterization of the WELAS and WHOPS}

In the following, the performance of the WELAS and the WHOPS is carefully assessed, including detailed uncertainty analyses. Table 1 summarizes the uncertainties of all relevant measured and derived quantities, including references to the corresponding sections and figures, where they are discussed.

\subsubsection{Counting efficiency}

The size-resolved counting efficiency of the WELAS2 was tested against a condensation particle counter (CPC 3025a, TSI Inc.) in order to verify the number concentration measurements and to determine the lower cut-off diameter (scattering cross section). The measured counting efficiency expressed as a function of the raw voltage signal $\varepsilon_{\mathrm{CE} \text {, meas }}\left(V_{\text {raw }}\right)$ is defined as

$\varepsilon_{\mathrm{CE}, \text { meas }}\left(V_{\text {raw }}\right)=\frac{n_{\text {Welas, raw }}\left(V_{\text {raw }}\right)}{n_{\mathrm{CPC}}}$,

where $n_{\text {Welas, raw }}\left(V_{\text {raw }}\right)$ is the particle number concentration measured by the WELAS for quasi-monodisperse ammonium sulfate particles size selected by a DMA that produces a certain raw voltage signal $V_{\text {raw }}$, and $n_{\mathrm{CPC}}$ is the corresponding value reported by the CPC. The raw voltage signal is chosen as a reference axis for the counting efficiency because $V_{\text {raw }}$, rather than particle size or scattering cross section, determines the detection probability. Note that $V_{\text {raw }}$ is inferred from the instrument output as described in Sect. 2.2.1. This calculation involves the WELAS-internal voltage calibration factor $C_{\mathrm{V}}$ (Eq. 8), which underlines that the knowledge of this factor is essential.

The plateau value of the measured WELAS counting efficiency reached for $V_{\text {raw }}>8 \mathrm{mV}$ is at $\sim 132 \%$ (Fig. 5). This 

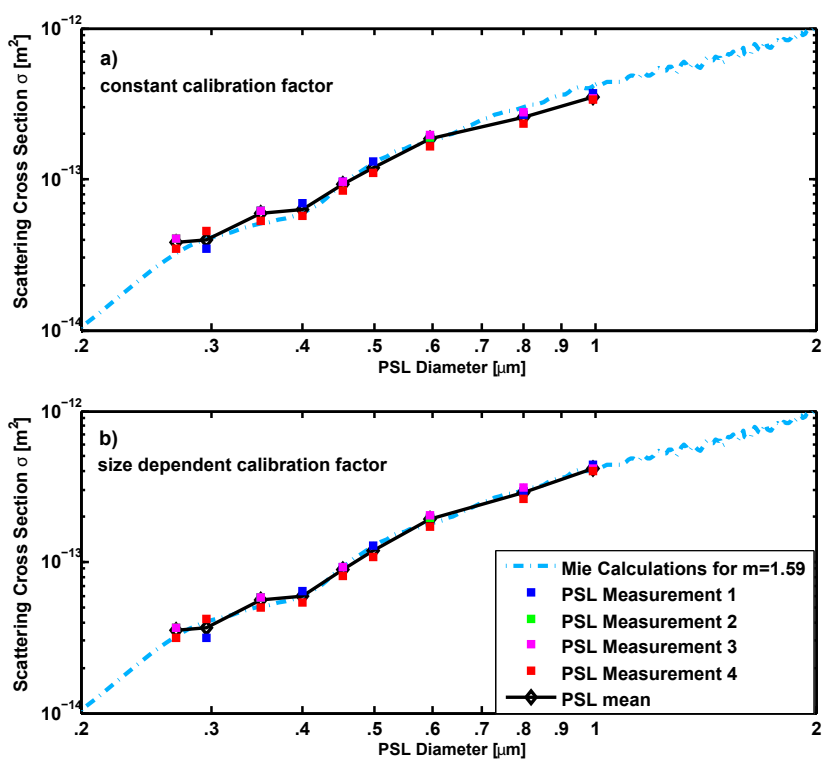

Figure 6. Comparison of measured and theoretical Mie curves calculated for $m=1.59$. The square markers, PSL measurements 14, show results from four different experiments and the black line, PSL mean, shows the mean value over the four experiments. In (a) a constant scattering cross section calibration factor of $C_{\sigma}=$ $3.71 \times 10^{-15} \mathrm{~m}^{2} \mathrm{mV}^{-1}$ was applied to analyze raw signals of the PSL measurements, while in (b) the voltage-dependent calibration function $C_{\sigma}\left(V_{\text {cal }}\right)$ described in Eq. (9) and Fig. 7 was applied.

means that the WELAS reports significantly higher number concentration readings than the CPC, which has an accuracy of $\pm 10 \%$. Such a bias was already observed by Heim et al. (2008), who explained it by the fact that the measuring volume in the WELAS used in the firmware calculations is incorrect, thus leading to a bias (fixed factor) in the concentration readings. As a consequence, the number concentration readings of the WELAS have to be corrected. The measurements shown in Fig. 5 were performed with several Xe lamps of the same type but different number of hours of operation. The counting efficiency as a function of $V_{\text {raw }}$ was equal within experimental uncertainty for all lamps, as expected. Consequently the efficiency curve presented in Fig. 5 is valid for all measurements carried out with this lamp type, as long as the transmission of the optical fiber cables remains constant.

The decrease of the efficiency for small particles (small $V_{\text {raw }}$ ), as seen in Fig. 5, can be explained as follows: the intensity of the light scattered by a particle has to be above a certain threshold to be detected by the scattering detector. Fluctuations of the ratio between scattering cross section and the raw voltage signal due to random noise are responsible for the fact that only a certain percentage of particles with a scattering cross section slightly above or below the lower detection limit will be measured or not. The finite width of the DMA transfer function has little influence here, as it is much smaller than the observed width of the lower cutoff of the WELAS. The raw voltages at 50,90 and $99 \%$ of the plateau value of the $\mathrm{CE}$ are 3.7, 5.2 and $7.7 \mathrm{mV}$, respectively (Fig. 5).

In the range of the lower detection limit, the CE for particles with a certain scattering cross section is expected to depend on the incident light intensity, as $V_{\text {raw }}$ is proportional to it (Eq. 3). However, the voltage calibration factor $C_{\mathrm{V}}$ varied less than $10 \%$, thus indicating a relatively low variability in lamp intensity. This makes an unambiguous assignment of optical diameters to the primary $V_{\text {raw }}$ axis possible (see additional abscissa scales in Fig. 5), using the mean value of $C_{\mathrm{V}}$ (2.23). The equivalent optical diameters for 50, 90 and $99 \%$ of the plateau value are $\sim 280, \sim 325$ and $\sim 395 \mathrm{~nm}$ for PSLs and $\sim 330, \sim 390$ and $\sim 430 \mathrm{~nm}$ for ammonium sulfate. This lower detection limit is significantly higher than specified by the manufacturer ( $200 \mathrm{~nm}$ for PSLs). The largest tested particle size corresponds to a PSL equivalent optical diameter of approximately $600 \mathrm{~nm}$. The counting efficiency is expected to remain constant at the observed plateau value for larger diameters, at least in the submicron size range, where potential impaction losses are unimportant. In the following, all data were corrected with the counting efficiency curve shown in Fig. 5, in order to correct for the concentration bias as well as the decreasing detection efficiency in the range of the lower detection limit.

\subsubsection{Calibration of the scattering cross section measurement}

The data analysis and calibration approach to retrieve quantitative scattering cross section values and optical diameters from the raw pulse height signals of the WELAS is described in detail in Sect. 2.2.1. The calibration factor $C_{\sigma}$ for the scattering cross section is obtained by measuring PSL spheres with a certified size (see Eq. 9). $C_{\sigma}$ is expected to be independent of the raw pulse height, i.e., independent of the size of the PSL spheres used to determine it. In order to test this, measurements with PSL spheres of nine different diameters between $260 \mathrm{~nm}$ and $1 \mu \mathrm{m}$ were performed, thereby covering the range of interest for the WHOPS measurements.

Figure 6 shows the comparison of the scattering cross section measured for the PSL particles with the theoretical Mie curve calculated for the WELAS specifications as described in Sect. 2.2. The squares in different colors depict four different experiments (distributed over the course of 5 months) and the abscissa denotes the PSL diameters. For Fig. 6a, a constant scattering cross section calibration factor $\left(C_{\sigma}=\right.$ $3.71 \times 10^{-15} \mathrm{~m}^{2} \mathrm{mV}^{-1}$ ) was applied in Eq. (10) to all experimental data $\left(V_{\mathrm{cal}}\right) . C_{\sigma}$ was chosen such to minimize the " $\chi$-square value" between the single points and theoretical curve. Figure 6a reveals that the main features of the theoretical Mie curve, like the shoulder between 300-400 nm, are well reproduced by the WELAS measurement. However, PSL particles with diameters above $800 \mathrm{~nm}$ seem to scatter about $10 \%$ less than predicted by Mie theory, and small par- 


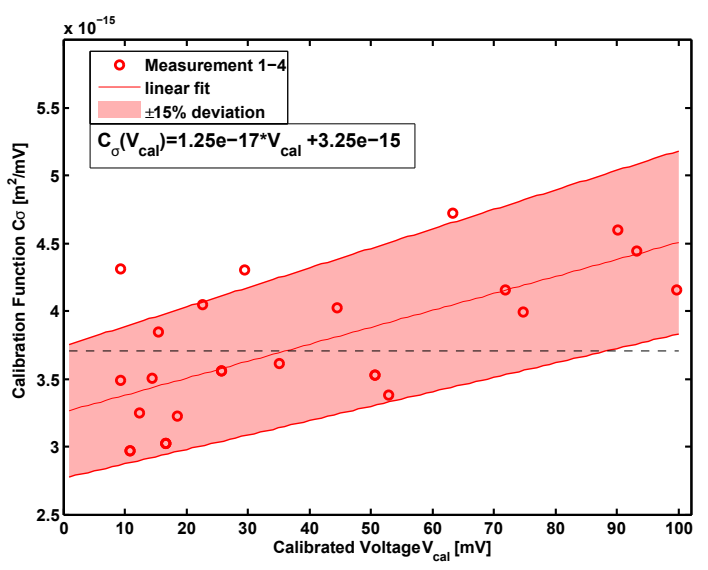

Figure 7. Actual ratio $\left(C_{\sigma}\right)$ between the calculated scattering cross section of PSL spheres and the calibrated voltage $\left(V_{\text {cal }}\right)$ measured by the light scattering detector plotted against $V_{\text {cal }}$. A linear fit (red line) through the data points is used as scattering cross section calibration function, $C_{\sigma}\left(V_{\text {cal }}\right)$, for the WELAS data analysis. Additionally, the shaded area represents $\pm 15 \%$ deviation around the fit. Approximately $85 \%$ of all data points fall within this uncertainty. The black dashed line depicts the constant calibration factor $C_{\sigma}=3.71 \times 10^{-15} \mathrm{~m}^{2} \mathrm{mV}^{-1}$ applied for Fig. 6 a.

ticles with diameters $<400 \mathrm{~nm}$ scatter approximately $10 \%$ more than expected. Sensitivity studies with variations of the input parameters in the Mie calculations showed that this systematic size-dependent bias cannot be significantly reduced by changing the scattering angles, the light spectrum, the index of refraction or assuming a narrow width of the PSL size distribution rather than a perfectly monodisperse aerosol. The exact reason for this minor disagreement is currently unknown. A possible explanation could be a non-linear behavior of the detector or electronic parts amplifying and processing these signals.

The systematic deviations observed in Fig. 6a imply that $C_{\sigma}$ is not a constant, contrary to expectations. Therefore, $C_{\sigma}$ was separately determined for each PSL data point, using Eq. (9), and plotted against the calibrated voltage (Fig. 7). This analysis reveals a systematic increase of the calibration factor $C_{\sigma}$ with increasing voltage signal. Therefore, we decided to use a voltage-dependent calibration function, $C_{\sigma}\left(V_{\text {cal }}\right)$, for the quantitative analysis of the WELAS signals (see Eq. 10). A linear fit, $C_{\sigma}\left(V_{\text {cal }}\right)\left[\frac{\mathrm{m}^{2}}{\mathrm{mV}}\right]=1.25 \times 10^{-17} \frac{\mathrm{m}^{2}}{(\mathrm{mV})^{2}} V_{\text {cal }}[\mathrm{mV}]+$ $3.25 \times 10^{-15} \frac{\mathrm{m}^{2}}{\mathrm{mV}}$, was selected for this calibration function. $85 \%$ of the measurement points lie within a $15 \%$ deviation band around the linear fit, indicating that the scattering cross section can be measured within an accuracy of around $15 \%$ (1 SD) when using this calibration function. Figure $6 \mathrm{~b}$ shows the PSL measurements analyzed with this calibration function. The fact that the systematic deviations presented in Fig. 6a disappeared in Fig. 6b justifies the use of this calibration function for all further data analysis.

\subsubsection{Uncertainty of the optical sizing of dry particles}

To retrieve the accuracy of the optical diameter measurement, the $15 \%$ accuracy of the measured scattering cross section is used as input for error propagation calculations. This uncertainty is present despite the calibration with Caldust. Nevertheless, repeated measurements of monodisperse ammonium sulfate particles revealed that the random variability, which corresponds to the precision of the scattering cross section measurement, amounts to less than $2 \%$ (1 SD). Figure 8 depicts the resulting estimated relative precision and accuracy of the dry optical diameters for four different indices of refraction: $1.59,1.50,1.40$ and 1.33 , representing PSL, the range often found for atmospheric aerosol and pure water, respectively. The uncertainty for optical diameters, resulting from a fixed uncertainty in the scattering cross section, depends on the local gradient of the Mie curve and thus on the particle size and index of refraction. This explains why the relative sizing precision and accuracy shown in Fig. 8 strongly depends on diameter and index of refraction. It is clearly visible that the precision of the optical sizing is much better than the accuracy. On average, the relative sizing accuracy is $9 \%$ for these indices of refraction in the range between $300 \mathrm{~nm}$ and $1 \mu \mathrm{m}$, with minimal and maximal values of 4 and $22 \%$, respectively, for $m=1.50$ at $0.469 \mu \mathrm{m}$ and $m=1.333$ at $0.300 \mu \mathrm{m}$. The precision amounts on average to $\sim 2 \%$ with minimal and maximal values of $0.1 \%$ and $5 \%$ (dashed lines in Fig. 8) and therefore plays a minor role (for measurements with sufficient counting statistics). The error analysis presented in Fig. 8 is only valid if particles have a constant index of refraction, e.g., for the optical sizing of a dry aerosol sample.

\subsubsection{Uncertainty of hygroscopic growth factors}

The Mie curves (green lines in Fig. 4) for solution droplets that grow by absorption of water are less steep than those for a constant index of refraction (red and blue curves in Fig. 4). Hence, for particles growing by water uptake the sizing accuracy has to be calculated with respect to the green lines. The red and green solid lines in Fig. 9a-b are equivalent to those in Fig. 4 but for using a dry index of refraction of 1.50. The Mie curves for solution droplets with a dry size of $300 \mathrm{~nm}$, solid green lines in Fig. 9a, have a local maximum at $\mathrm{GF}=1$ and a local minimum at $\mathrm{GF}=1.2$. This results in sizing ambiguities for solution droplets with a scattering cross section value in between those of the local extremes, i.e., for the growth factor range $\mathrm{GF}<1.4$. This "ambiguity uncertainty" is shown as red shading in Fig. 9c. For particles with a true GF of $1.0<\mathrm{GF}<1.2$ (range between the positions of the local extremes), the ambiguity can potentially result in an over- or undersizing, while for particles with GF between 1.2 and 1.4 the ambiguity results in potential undersizing. The associated relative uncertainty is larger than $\pm 20 \%$. Therefore we only report data for GF $>1.4$ in the case of $300 \mathrm{~nm}$ 


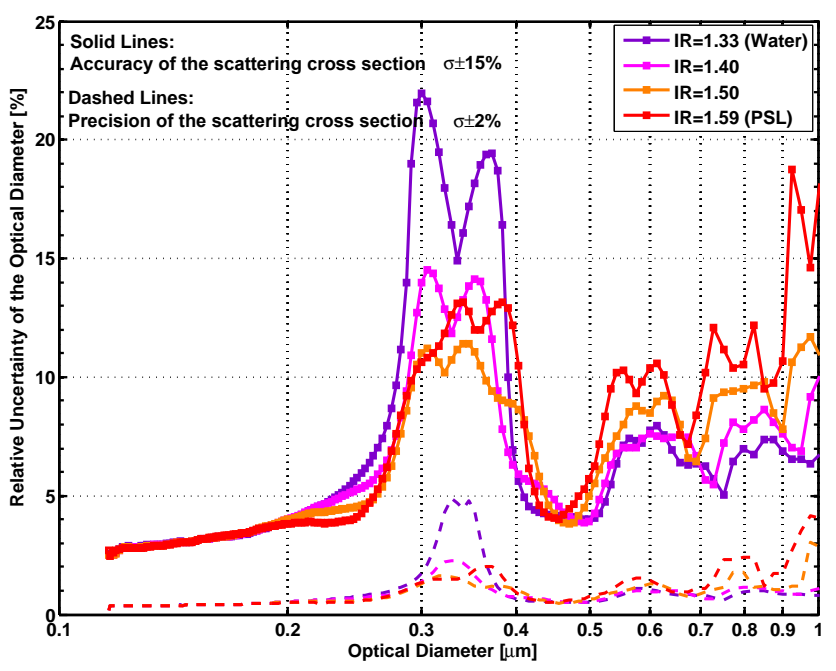

Figure 8. Relative uncertainty of the optical sizing by the WELAS as a function of optical diameter and for dry particles with different indices of refraction. The accuracy estimate (solid lines) is based on error propagation calculations for a fixed accuracy of $\pm 15 \%$ for the measured scattering cross sections (note: the $y$ axis shows the absolute value of the larger relative size change when disturbing the scattering cross section by \pm its uncertainty). Additionally, the precision of the optical sizing (dashed lines) is illustrated.

particles. A low ambiguity uncertainty of $\sim 6 \%$ also occurs for $\mathrm{GF}>4.8$, which is only relevant for very hygroscopic particles at very high relative humidity. For the $500 \mathrm{~nm}$ particles, an ambiguity uncertainty of mostly $<\sim 7 \%$ occurs in the range $\mathrm{GF} \geq 2.8$ for particles with $m_{\text {dry }}=1.50$ (Fig. 9d). In case of higher $m_{\text {dry }}$, ambiguity also becomes an issue in the range $\mathrm{GF}<\sim 1.15$ (see dashed green line in Fig. 4a).

The precision of calibrated scattering cross section measurements with the WELAS is $\sim \pm 2 \%$ ( $1 \mathrm{SD}$; see Sect. 3.1.3). The associated precision of inferred GFs (violet curves in Fig. 9c-d) is obtained by changing the scattering cross section $\sigma_{\mathrm{s}}$ by $\pm 2 \%$ (note that, in order to separate the uncertainties in GF due to different causes, the Mie curves were smoothed in the upper GF range before inferring the GF dependence of the precision and accuracy). The precision typically causes less than $3 \%$ GF uncertainty, except for $D_{\text {dry }}=500 \mathrm{~nm}$ and $\mathrm{GF}<1.4$, where this uncertainty increases by up to $6 \%$ due to the lower gradient of the Mie curve. The accuracy of the scattering cross section measurement by the WELAS ( $1 \mathrm{SD}= \pm 15 \%$; see Fig. 7 and discussion above) is more relevant than the precision for the uncertainty of GFs determined with the WHOPS. An absolute scattering cross section calibration bias is partially accounted for by adjusting the index of refraction of the dry particles according to the dry-mode WHOPS measurement. This ensures that no GF bias occurs at GF $=1$ (cf. blue curve in Fig. 9d). However, the Mie curves for the adjusted index of refraction (dashed and dash-dotted green lines in Fig. 9ab for $m_{\text {dry }}=1.53$ and 1.47 and $m_{\text {dry }}=1.53$ and 1.46 , re- spectively), have a slightly different slope than the "true" Mie curve for $m_{\text {dry }}=1.50$, such that a scattering cross section calibration bias still causes a GF uncertainty for GF $>1$. Comparing all sources of uncertainty in the GF retrieval reveals that the accuracy of the scattering cross section calibration gives the dominant contribution except for GF $<\sim 1.4$ and $D_{\text {dry }}=300 \mathrm{~nm}$ (any $m_{\text {dry }}$ ), where the ambiguity uncertainty dominates. Overall, the accuracy of the retrieved GF is around $5-12 \%$ in the ranges without substantial sizing ambiguity, depending on dry size, GF and effective index of refraction (uncertainty analyses for indices of refraction are presented in the Supplement). However, it is important to note that the accuracy of the RH measurement ( $\pm 2 \%$ ) propagates to a corresponding relative GF uncertainty of 12-17\% (at $\mathrm{RH}=95 \%$ and $\kappa$ values between 0.1 and 0.5 ).

\subsubsection{Retrieval of the index of refraction of PSL and ammonium sulfate}

The dry effective index of refraction $\left(m_{\text {dry }}\right)$ of an aerosol sample can be retrieved from the dry-mode WHOPS measurement, as described in Sect. 2.2.2. To verify this procedure, tests were performed in the laboratory with PSL spheres and size-selected (by the DMA in the WHOPS) ammonium sulfate $\left(\left(\mathrm{NH}_{4}\right)_{2} \mathrm{SO}_{4}\right)$ particles, which were prepared as described in Sect. 2.3. Note that the size-selected ammonium sulfate aerosol sample also contains multiply charged particles which are larger than the singly charged particles. However, they appear as a well-separated mode in the WELAS size distribution measurement and are neglected for this analysis.

Figure 10 illustrates the retrieved effective indices of refraction for particle diameters between 290 and $1000 \mathrm{~nm}$. The four different experiments with certified PSL spheres are the same as those already shown in Figs. 6 and 7. The retrieved index of refraction for PSLs was found to be $m=1.60 \pm 0.04$ (mean $\pm 1 \mathrm{SD}$ ), which agrees well with the literature value of $m \approx 1.59$ (see Sect. 2.2.1). These four PSL experiments were used to determine the scattering cross section calibration function $C_{\sigma}\left(V_{\text {cal }}\right)$ for the WELAS (see Sect. 2.2.1/Eq. 10 and Sect. 3.1.2/Fig. 7). Therefore, the retrieval of the index of refraction for the very same PSL experiments is an internal consistency check of the instrument calibration and data analysis approaches. Besides this, the scatter of the PSL data points in Fig. 10 reveals the precision of the retrieved index of refraction $(1 \mathrm{SD} \approx \pm 0.04$ absolute), which is given by the random noise of the individual PSL data points around the mean calibration function (see Fig. 7).

The dry-mode WHOPS measurements of the size-selected ammonium sulfate particles provide an independent test of the index of refraction retrieval for an aerosol sample that has different optical properties and that was not used for calibration purposes (except for testing the counting efficiency, which is independent of the optical sizing). The retrieved index of refraction for dry ammonium sulfate particles is found 

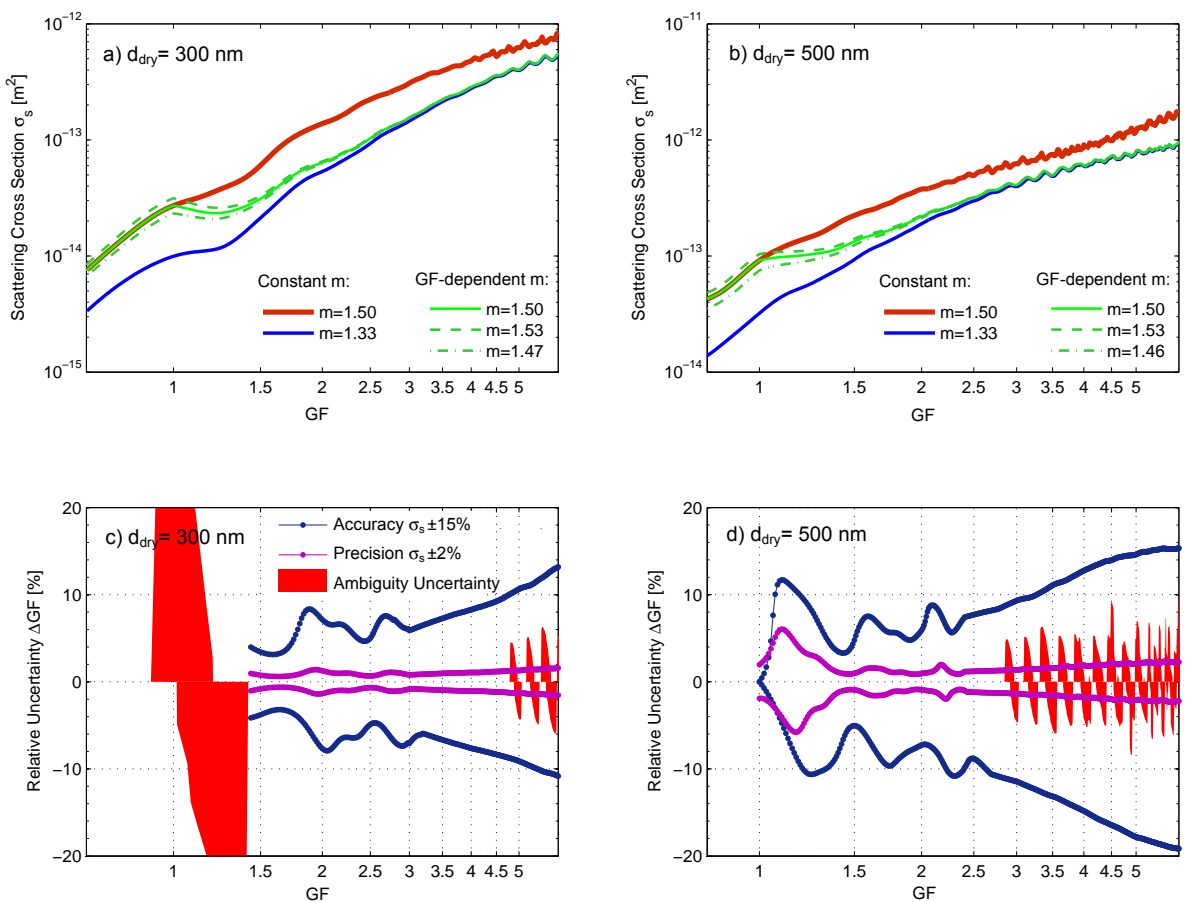

Figure 9. Optical sizing of solution droplets. Panels (a) and (b) show theoretically calculated scattering cross sections versus growth factor (solid green lines) for the example of particles with a dry index of refraction of 1.50 and dry diameters of 300 and $500 \mathrm{~nm}$, respectively. The solid red and blue lines are theoretical curves for particles with a constant index of refraction, and the green lines indicate the effect of a calibration bias (see text for details). Panels (c) and (d) display the sizing uncertainties due to different causes for the example particles from panels (a) and (b), respectively.

to be $m=1.49 \pm 0.02$ (mean $\pm 1 \mathrm{SD}$ ), which is $\sim 2.3 \%$ lower than the mean literature value of $m=1.53$ (Toon et al., 1976) found by weighing the stated values for the wavelength range of interest. This systematic difference is small given the fact that the selected mobility diameter is tainted with some uncertainty (accuracy is assumed to be $<5 \%$ ) and that part of it can likely be explained by the slight non-sphericity of dry ammonium sulfate particles produced by nebulizing a solution and subsequent drying. Zelenyuk et al. (2006) reported a decreasing effective density with increasing mobility diameter for ammonium sulfate particles. This is qualitatively consistent with the observed increasingly negative bias in the retrieved index of refraction, though non-sphericity may also have some influence on the light scattering cross sections.

In summary, the retrieval of the effective index of refraction of the dry particles gives a good approximation, given the fact that the main use of it is to ensure that meaningful growth factors are obtained by relating the inferred optical diameters to the selected mobility diameters, as described in Sect. 2.2.2.

\subsubsection{Measured hygroscopicity of ammonium sulfate particles}

The accuracy of hygroscopic growth factors measured by the WHOPS in the wet mode was verified against Köhler theory

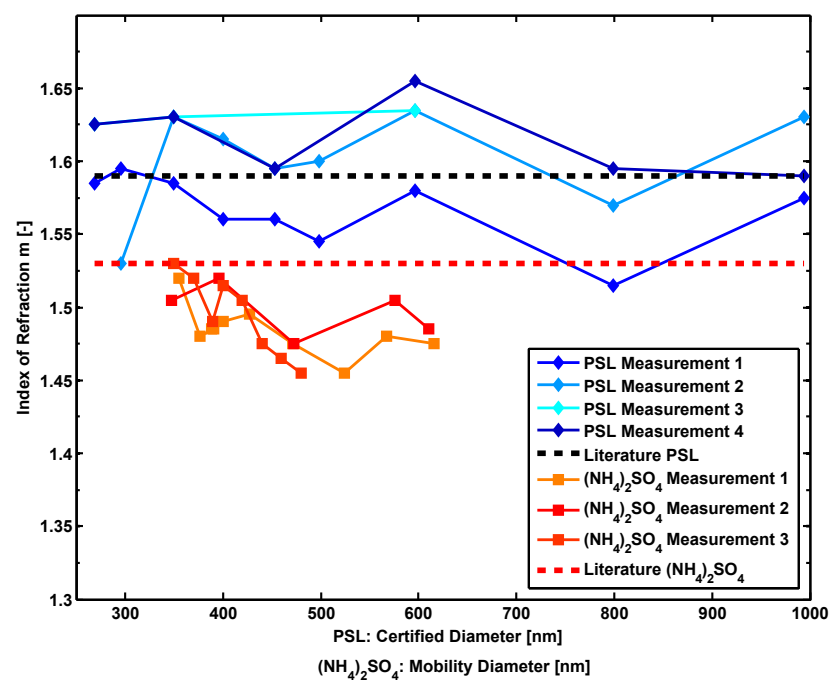

Figure 10. Retrieved refractive indices for dry, nebulized ammonium sulfate, $\left(\mathrm{NH}_{4}\right)_{2} \mathrm{SO}_{4}$ (reddish colors; plotted against mobility diameter) and different polystyrene latex spheres, PSL (bluish colors; plotted against certified diameter) measurements.

using pure ammonium sulfate particles which were generated as described in Sect. 2.3. The WHOPS measurements were analyzed using the approach presented in Sect. 2.2.2 

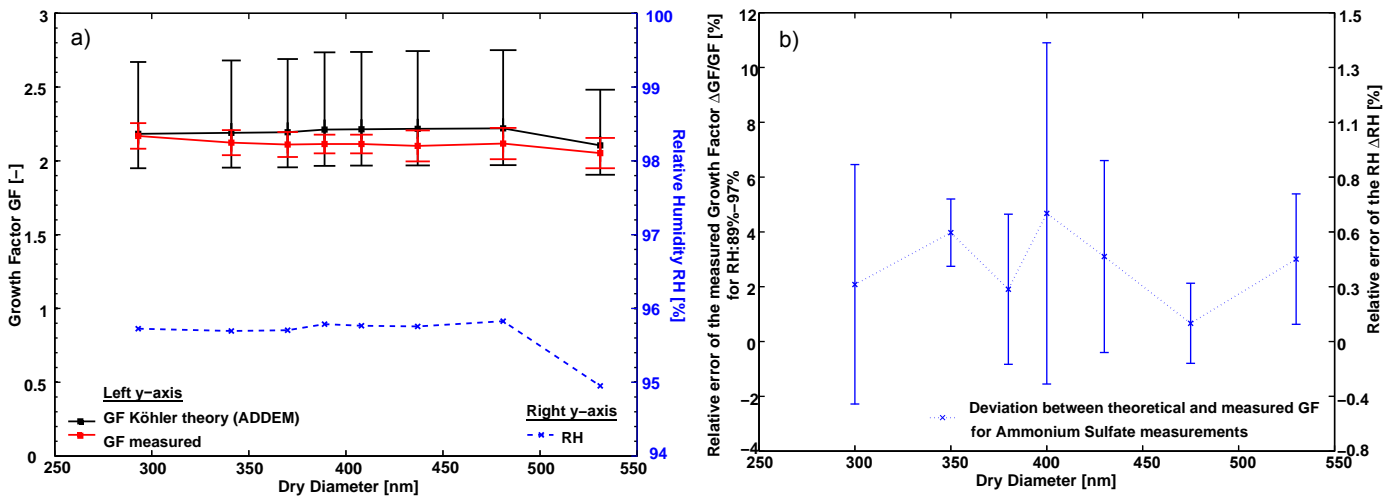

Figure 11. (a) Shows a typical example of the hygroscopic growth factors (red markers) measured by the WHOPS for pure ammonium sulfate particles of different dry sizes along with the relevant relative humidity (blue markers) simultaneously measured in the WHOPS. In (a) the error bars around the measured GFs indicate the accuracy of 6-10\% as described in Sect. 3.1.3. The theoretical growth factors (ADDEM Model; Topping et al., 2005) corresponding to the measured RH are shown in black, where the error bars indicate the propagated uncertainty corresponding to an experimental accuracy of the measured relative humidity of $\sim \pm 2 \%$ (absolute). The markers and error bars shown in (b) indicate the statistics (mean and standard deviation from eight independent experiments) of the relative difference between measured and theoretical growth factor of ammonium sulfate particles at RHs between 89 and $97 \%$ for different dry sizes. The right $y$ axis shows the hypothetical $\mathrm{RH}$ bias at $\mathrm{RH}=95 \%$, which would explain the corresponding observed GF bias shown on the left $y$ axis.

and Fig. 3, i.e., accounting for the effect of absorbed water on the index of refraction of the solution droplets. Figure 11a shows a typical example of the GFs measured by the WHOPS for different dry particles diameters (red markers) along with the relevant relative humidity (blue markers) simultaneously measured in the WHOPS. The error bars on the measured GFs reflect the accuracy of $6-10 \%$ as discussed in Sect. 3.1.4 (see also Fig. 9). The corresponding theoretical growth factors, calculated for the measured RH using Köhler theory (ADDEM Model; Topping et al., 2005), are shown with black markers. As explained in Sect. 2.1, the RH sensors applied in the WHOPS have an absolute accuracy of $\sim \pm 2 \% \mathrm{RH}$. The error bars around the theoretical GFs depict the propagated uncertainty corresponding to this $\mathrm{RH}$ accuracy (note that the propagated uncertainty at $\mathrm{RH} \sim 96 \%$ is larger than that at $\mathrm{RH}=95 \%$, which is listed in Table 1). The agreement between the measured and theoretical GF is very good for the example shown in Fig. 11a. In order to determine the long-term performance of the WHOPS, results of eight independent ammonium sulfate experiments distributed over 7 months are shown in Fig. 11b. The crosses depict the mean relative deviation of the measured GF from the theoretical value at the same RH (between 89-97\%), while the error bars show the standard deviation. The right $y$ axis in Fig. 11b explains what absolute RH bias would be necessary to explain the corresponding GF bias shown on the left $y$ axis at an $\mathrm{RH}$ of $95 \%$. The mean relative deviation of measured GFs from theory is almost negligible with values between 0 and $4.5 \%$ for different dry diameters, which corresponds to an absolute RH bias between 0 and $0.7 \%$. The fact that also all error bars fall between -2 and $+11 \%$ GF bias, which corresponds to -0.4 and $+1.4 \%$ absolute $\mathrm{RH}$ bias, indicates that all individual data points fall within the expected uncertainty taking into account that the accuracy of the RH measurement, which is likely the main limiting factor of growth factor measurements by the WHOPS, is estimated to be as much as $\pm 2 \%$ (absolute).

Figure 11 shows that it is possible to accurately measure the GF of pure ammonium sulfate particles between 300 and $531 \mathrm{~nm}$. The measurements for a dry diameter as small as $300 \mathrm{~nm}$ are only possible since the ammonium sulfate solution droplets grow clearly above the lower WELAS detection limit, which is at $\sim 390 \mathrm{~nm}$ for dry ammonium sulfate particles (Sect. 3.1.1 and Fig. 5). Furthermore, the GF of $300 \mathrm{~nm}$ ammonium sulfate particles is also above the threshold, which makes unambiguous optical sizing possible even at this dry diameter (Sect. 2.2.2 and Fig. 4). However, it is not possible to measure the complete growth factor distribution of aerosol samples that contain non- or only slightly hygroscopic particles for dry sizes below $\sim 400 \mathrm{~nm}$, as they would remain undetected by the WELAS, thereby biasing the measured GF distribution.

\subsection{First field measurements}

Here we present first results from an airborne application of the WHOPS on board the Zeppelin NT during one longdistance flight in the Netherlands which took place in the afternoon on 22 May 2012. The Zeppelin started at the international airport of Rotterdam The Hague, then reached the Cabauw Experimental Site for Atmospheric Research (CESAR) $\sim 40 \mathrm{~km}$ east of Rotterdam, where it turned back westwards, passed Rotterdam again, flew over the North Sea until $\sim 20 \mathrm{~km}$ from the coast, before turning back eastwards and finally landed at the airport (see Fig. 12a and b). The aver- 
age altitude flown was $200 \mathrm{~m}$ above ground, except for the part over the sea, marked with a red circle in Fig. 12a, where a short height profile was performed reaching up to $700 \mathrm{~m}$ above ground, before flying back to the airport at an altitude of $200 \mathrm{~m}$ above ground.

Figure 12b displays the mean GFs at $95 \% \mathrm{RH}$ (color coded, averaged over one measurement cycle of $200 \mathrm{~s}$ ) measured by the WHOPS along the flight track for $500 \mathrm{~nm}$ particles. The measured GFs were not recalculated for small deviations between the target $\mathrm{RH}$ of $95 \%$ and the actual $\mathrm{RH}$ measured in the WHOPS (corrected for equilibration time effects), because the latter was always within $95 \pm 0.6 \%$. For the $500 \mathrm{~nm}$ particles, mean GFs were found to be between 1.79 and 2.43, with a median value of 2.02. In order to compare the aerosol hygroscopicity measurements made in this study with literature data, the hygroscopicity parameter $\kappa$ was calculated from the measured mean GF according to Eqs. (2) and (3) in Sect. 1. The WHOPS-derived $\kappa$ values are listed in Table 2, along with literature data for similar aerosol types. The WHOPS values reach from $\kappa=0.25$ to 0.75 , with a median $\kappa$ of 0.38 for $D_{\text {dry }}=500 \mathrm{~nm}$. This matches well with the range of $\kappa$ values of $0.3 \pm 0.1($ mean $\pm \mathrm{SD})$ and $0.7 \pm 0.2$ that are considered to be representative for continental and marine aerosols, respectively, based on a review of cloud condensation nuclei measurements (Andreae and Rosenfeld, 2008). Pringle et al. (2010) performed global model simulations and reported a $\kappa$ value of $0.27 \pm 0.21$ for continental aerosol. Higher $\kappa$ values of $0.4-0.6$ and $0.9-1.0$ were reported for mixed marine/continental aerosols and remote marine aerosols, respectively. These values cover the range from in situ measurements well.

The time series of the measured mean GFs and $\kappa$ values for $500 \mathrm{~nm}$ particles is shown in Fig. 12e (black curve). The error bars indicate the accuracy of $\pm 10 \%$ ( $1 \mathrm{SD}$; see Sect. 3.1.2). Higher $\kappa$ values (median $=0.55$ ) were found during the first part of the flight, when the Zeppelin headed inland towards Cabauw and back to Rotterdam (from now on referred to as "Part 1 "), while lower $\kappa$ values (median $=0.31$ ) were found during the second part of the flight, which was directed towards the sea and back to Rotterdam (from now on referred to as "Part 2"). The prevailing local wind direction (arrows in Fig. 12c), measured on board the Zeppelin NT, differed clearly between these two regions (the change in local wind direction is marked by the dashed gray line): during "Part 1" northwesterly winds were dominant, while during "Part 2" northeasterly winds prevailed. Besides, the wind speed is illustrated in Fig. 12c, showing generally low values $\left(2-4 \mathrm{~m} \mathrm{~s}^{-1}\right)$. The number concentration of particles with $D>300 \mathrm{~nm}$ obtained from the polydisperse WELAS measurement (turquoise line in Fig. 12d) increases sharply just after the local wind direction changes. This gives clear evidence that the Zeppelin NT entered a different air mass during the second part of the flight.

Back trajectory analysis (not shown) was performed for different places and time periods and revealed that the probed air masses had maritime and/or continental influences. However, the whole flight was dominated by low wind speeds and changes in the local wind direction were not captured by the HYSPLIT model such that the model output was not reliable.

Figure 12f illustrates the averaged GF distribution (GFPDF) for a dry diameter of $500 \mathrm{~nm}$, where the turquoise line and the solid blue line illustrate the results for "Part 1" and "Part 2", respectively. Particles covering the whole GF range between approximately 1 and 3 were observed. This does not necessarily imply external mixture at a certain time. However, the fact that particles with GFs substantially smaller and larger than the observed minimal and maximal mean GF occurred indicates that the aerosol was at least sometimes externally mixed (a time-resolved analysis of the mixing state is not possible due to the limited counting statistics).

On average, about $15 \%$ of $500 \mathrm{~nm}$ dry particles had GF $<$ 1.1 , which could be explained with externally mixed dust (e.g., Herich et al., 2009), fresh soot (e.g., Tritscher et al., 2011) or biological particles (e.g., Després et al., 2012). Mineral dust and possibly biological material are more likely, as the size distribution of such particles is known to extend down to the submicron size range (Després et al., 2012; Mahowald et al., 2014), while fresh soot particles typically show up at smaller sizes $(\sim 100 \mathrm{~nm}$; Rose et al., 2006). Around $74 \%$ of the $500 \mathrm{~nm}$ particles had GF $>1.5$ at the dry size of $500 \mathrm{~nm}$. These particles must have contained a high fraction of inorganic salts, which are the most hygroscopic aerosol components (e.g., Topping et al., 2005). The remaining $11 \%$ of the $500 \mathrm{~nm}$ particles had GFs between 1.1 and 1.5, most likely an internal mixture of organic/inorganic compounds (e.g., Gysel et al., 2004; Meyer et al., 2009). The dominance of more hygroscopic particles explains the relatively large mean and median GFs and $\kappa$ values presented above. One clear distinction between the two air masses is the shift of the more hygroscopic fraction to smaller GFs during "Part 2" compared to "Part 1", while the non- and less-hygroscopic fractions remained essentially unchanged. During "Part 1", the main, more hygroscopic mode peaked at a GF of $\sim 2.5$ $(\kappa \sim 0.8)$. This is more hygroscopic than, e.g., pure ammonium sulfate or ammonium nitrate particles (e.g., Petters and Kreidenweis, 2007; Topping et al., 2005) and can only be explained with very hygroscopic sea-salt particles (pure $\mathrm{NaCl}$, $\mathrm{NaNO}_{3}$ and $\mathrm{Na}_{2} \mathrm{SO}_{4}$ particles have $\kappa$ values at $\mathrm{RH}=95 \%$ of $1.32,0.86$ and 0.67 , respectively). Sea-salt particles are frequently observed in the accumulation mode aerosol of marine environments (Swietlicki et al., 2008). During "Part 2", the main, more hygroscopic mode shifted towards smaller GFs peaking at a GF of $\sim 2(\kappa \sim 0.4)$, which is typical for a continental background aerosol (Swietlicki et al., 2008) although aged sea-salt particles with a substantial organic fraction would also be possible.

For the $300 \mathrm{~nm}$ particles, shown in Fig. 12g, the GFPDF could only be measured by the WHOPS for the range GF $>1.5$ due to the lower detection limit of the WELAS (see Sect. 3.1.4). This leads to incomplete GF-PDFs and thus 

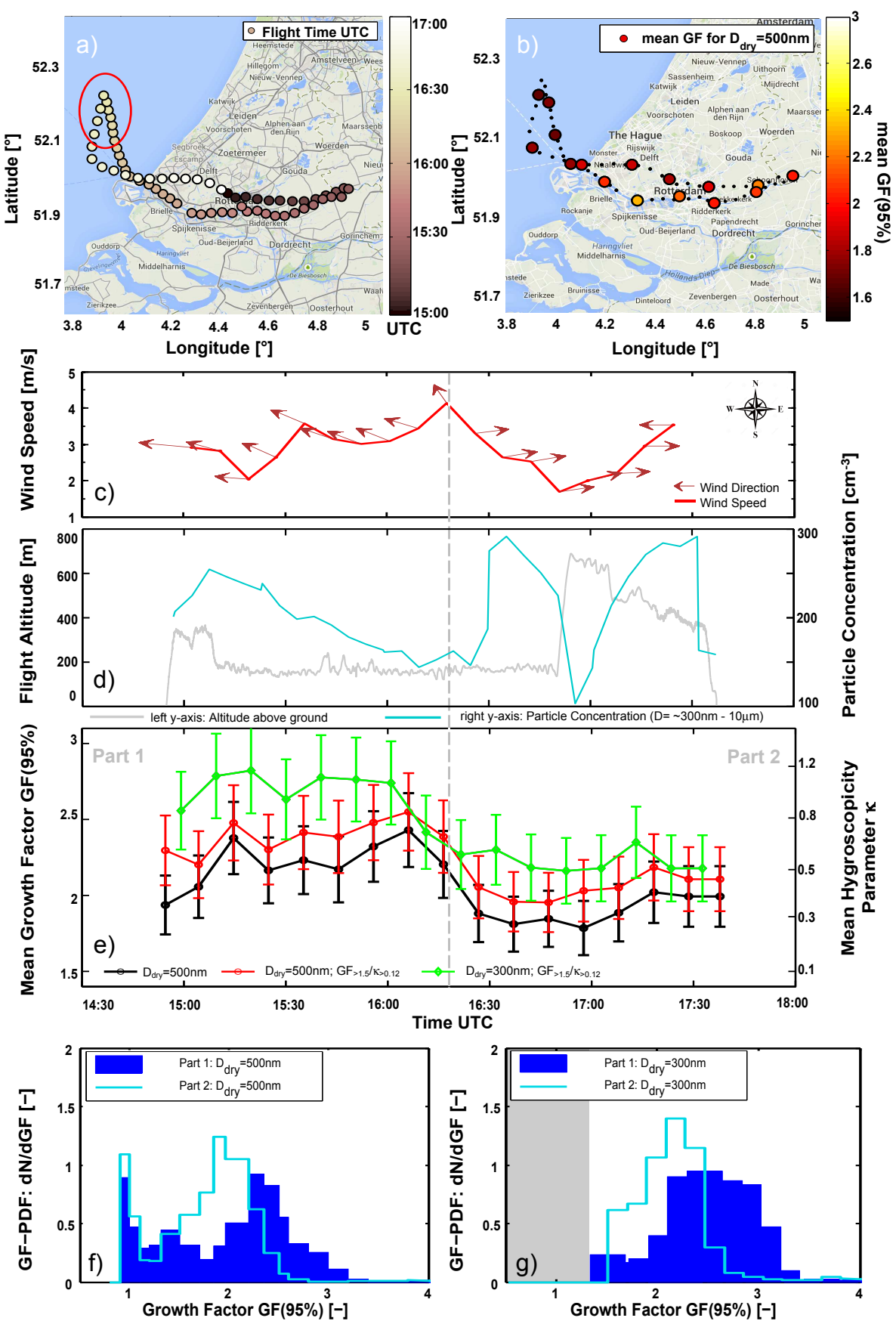

Figure 12. Example of airborne WHOPS measurements on board the Zeppelin NT from 22 May 2012 in the Netherlands; (a) flight track color coded by UTC time; (b) mean GFs (color coded) at RH $=95 \%$ for $D_{\text {dry }}=500 \mathrm{~nm}$ particles; (c) time series of the local wind speed (red curve) and wind direction (red arrows) measured on board the Zeppelin NT; (d) time series of the flight altitude (gray line) and number concentration of particles with $D>300 \mathrm{~nm}$ measured by the polydisperse WELAS1 (turquoise line); (e) time series of the measured mean GF (left axis) and corresponding $\kappa$ values (right axis) for the selected particle size of $500 \mathrm{~nm}$; additionally the mean GF of all particles with GF $>1.5(\kappa>0.12$; lower detection limit when selecting $300 \mathrm{~nm}$ particles) is shown for the $300 \mathrm{~nm}$ and $500 \mathrm{~nm}$ particles; the gray dashed line across panels (c), (d) and (e) marks the point in time when the local wind direction changed between the first and second part of the flight; (f) GF-PDF for humidified $500 \mathrm{~nm}$ particles separately averaged over "Part 1" and "Part 2"; (g) equivalent to (f) but showing results for $300 \mathrm{~nm}$ particles; the gray area covers the GF range that cannot be reliably detected for this particle size. 
Table 2. $\kappa$ values derived from different measurements at the CESAR site in Cabauw in this and previous studies plus simulated global values.

\begin{tabular}{lrrrll}
\hline Compound & $\kappa_{\text {low }}$ & $\kappa_{\text {up }}$ & $\kappa_{\text {median }}$ & Instrument & Dry diameter [nm] \\
\hline Cabauw (ambient) & 0.25 & 0.75 & 0.38 & WHOPS (this study) & 500 \\
Cabauw (ambient) & $0.14^{\mathrm{a}}$ & $0.53^{\mathrm{a}}$ & $0.29^{\mathrm{a}}$ & Wet-Neph & mean of size distribution \\
Cabauw (ambient) & $0.11^{\mathrm{b}}$ & $0.44^{\mathrm{b}}$ & $0.26^{\mathrm{b}}$ & HTDMA & 165 \\
Global continental & $0.06^{\mathrm{c}}$ & $0.48^{\mathrm{c}}$ & & EMAC Model & $10-1000$ \\
Global remote marine & $0.90^{\mathrm{c}}$ & $1.00^{\mathrm{c}}$ & & EMAC Model & $10-1000$ \\
Global mixed marine/continental & $0.40^{\mathrm{c}}$ & $0.60^{\mathrm{c}}$ & & EMAC Model & $10-1000$ \\
\hline & $\kappa_{\text {mean }}$ & $\kappa_{\text {std }}$ & & & \\
\hline Continental (ambient) & $0.3^{\mathrm{d}}$ & $0.1^{\mathrm{d}}$ & & review - various methods & $<300$ \\
Marine (ambient) & $0.7^{\mathrm{d}}$ & $0.2^{\mathrm{d}}$ & & review - various methods & $<300$ \\
\hline
\end{tabular}

a Zieger et al. (2011), $\kappa$ calculated from GF retrieved from Wet-Neph data from their Fig. 6.

b Zieger et al. (2011), $\kappa$ calculated from HTDMA data from their Fig. 6.

c Pringle et al. (2010), range of $\kappa$ from Table 1 simulated at Earth's surface level from ECHAM/MESSy Atmospheric Chemistry (EMAC) model to simulate global fields of the effective hygroscopicity parameter $\kappa$ which approximately describes the influence of chemical composition on the cloud condensation nucleus activity of aerosol particles.

d Andreae and Rosenfeld (2008), summary for $\kappa$ values from Sect. 2.1.3 from several HTDMA and cloud condensation nuclei counter measurements.

also to a high bias in the inferred mean GFs. Nevertheless, these measurements still provide some useful insight. The GF-PDF shown in Fig. 12g also reveals a similar trend with the air mass change as seen for the $500 \mathrm{~nm}$ particles diameter: the more hygroscopic mode shifts from very high GFs during "Part 1" towards slightly lower GFs during "Part 2". Figure $12 \mathrm{~g}$ further reveals that the averaged GF-PDF in the range GF $>1.5$ is quite similar for the $300 \mathrm{~nm}$ and $500 \mathrm{~nm}$ particles, although the $300 \mathrm{~nm}$ particles seem to be shifted towards just slightly larger growth factors. The lower detection limit of the WELAS made it impossible to determine whether the number fraction of particles with $\mathrm{GF}<1.5$ is also similar for the two investigated dry sizes.

For a spatially resolved comparison of the size dependence of particle hygroscopicity, Fig. 12e additionally contains the mean GF of those particles with GF $>1.5$ for the dry diameters $300 \mathrm{~nm}$ (green symbols) and $500 \mathrm{~nm}$ (red symbols). This comparison reveals a similar spatial pattern with two distinct air mass types for both sizes. The mean GF values of the more hygroscopic particle fraction are just slightly larger at $300 \mathrm{~nm}$ dry diameter compared to $500 \mathrm{~nm}$, as already seen from the GF-PDFs shown in Fig. $12 \mathrm{f}$ and g. However, this subtle difference is within the experimental uncertainty of the WHOPS (see error bars in Fig. 12e). The almost constant difference between the black and red lines in Fig. 12e further confirms that the change in the mean GF of the $500 \mathrm{~nm}$ particles between the two parts of the flight can mostly be attributed to a shift of the more hygroscopic mode with GF $>1.5$, while the number fraction and GF of the particles in the range $\mathrm{GF}<1.5$ stayed quite constant over the whole flight, in agreement with Fig. $12 \mathrm{f}$ and g.

Zieger et al. (2011) reported aerosol hygroscopicity data from previous measurements at the CESAR site in Cabauw, at which the Zeppelin passed by in this study, determined with two different experimental techniques: monodisperse HTDMA measurements at $\mathrm{RH}=90 \%$ and polydisperse humidified nephelometer (Wet-Neph) measurements. These two approaches differ from the WHOPS technique with regard to the selected/representative dry diameters as well as the set RH (see Table 2 for more details).

The $\kappa$ values determined by Zieger et al. (2011) using the Wet-Neph and size distribution measurements were between 0.14 and 0.53 (median $=0.29$ ) and those derived from the HTDMA measurement lay between 0.11 and 0.44 (median $=0.26$ ), which compares well to the WHOPS data of this study, even though these measurements were taken at different times and dry sizes. The lower $\kappa$ values of the HTDMA were explained by the not fully detected contribution of sea salt above $165 \mathrm{~nm}$ (maximum dry diameter set in the HTDMA). Zieger et al. (2011) could further classify the observations into different air mass types with distinct aerosol hygroscopic properties, including marine, polluted marine and continental influence. Within this study, it was further observed that the particle hygroscopicity was increased during periods with marine air masses. This further supports the above interpretation of the two air mass types encountered in this study during the first and second parts of the flight.

Using the approach described in Sect. 2.2.2, it was also possible for the $500 \mathrm{~nm}$ particles to retrieve the effective index of refraction of the dry particles which was found to be $1.42 \pm 0.01$ (mean $\pm 1 \mathrm{SD}$; the estimated accuracy is \pm 0.04 ) for either part of the flight. This compares well with literature values for the index of refraction in the visible wavelength range of 1.44-1.52 for marine aerosol (Stock et al., 2011), while it is somewhat lower than values of 1.5-1.57 reported for continental aerosol (Stock et al., 2011; Ebert et al., 2002). 


\section{Conclusions}

We developed a new airborne instrument to quantify the hygroscopic growth of large aerosol particles above a mobility diameter of approximately $280 \mathrm{~nm}$ at defined high relative humidity, typically around $95 \%$. One main advantage is that the system is able to select dry particle sizes up to approximately $630 \mathrm{~nm}$ and therefore to investigate the optical and hygroscopic properties of particles in the optically relevant size range. Besides, information on the mixing state and the particles' refractive index can be inferred. The instrument was further employed in a Zeppelin NT to perform vertical and horizontal profiles of the hygroscopic growth factor in the lower part of the troposphere.

The calibration and data analysis procedures for the optical sizing were successfully verified in laboratory experiments using monodisperse PSL and ammonium sulfate particles. The accuracy of the optical sizing of dry particles is found to range between 4 and $22 \%$, depending on the actual size and index of refraction of the particles. The accuracy of GFs retrieved from WHOPS measurements is limited by the scattering cross section calibration accuracy of the WELAS, except for dry particles with diameters smaller than $\sim 400 \mathrm{~nm}$, where ambiguity errors become dominant in the range $\mathrm{GF}<\sim 1.4$. However, the $\mathrm{RH}$ at which the GF is measured is also tainted with uncertainty. Propagating the $\mathrm{RH}$ accuracy to a GF uncertainty revealed that the RH uncertainty gives the dominant contribution to overall uncertainty for WHOPS measurements at RH $>\sim 93 \%$. Measured hygroscopic growth factors of pure ammonium sulfate particles agreed on average within $3 \%$ with the theory, with a maximal difference of $8 \%$. The index of refraction retrieved for pure ammonium sulfate particles agreed within $2 \%$ with literature values. Both results are within the experimental uncertainty.

During first airborne measurements in the Netherlands, GFs (mean value of the GF distribution) at $\mathrm{RH}=95 \%$ between 1.79 and 2.43 with a median of 2.02 for particles with a dry diameter of $500 \mathrm{~nm}$ were observed. The measured growth factor distributions for these particles revealed an externally mixed aerosol including clear evidence for the presence of sea-salt particles at certain times. The hygroscopic properties observed in this study compare well with literature values from previous ground-based measurements in the area. The mean effective index of refraction for $500 \mathrm{~nm}$ particles was found to be $1.42 \pm 0.04$ (real part).

\section{The Supplement related to this article is available online at doi:10.5194/amt-8-921-2015-supplement.}

Acknowledgements. This work was supported by the EC project PEGASOS, funded by the European Commission under the Framework Programme 7 (FP7-ENV-2010-265148). We thank all PEGASOS participants for the excellent team work during the campaigns.
Additionally we thank Frank Holland for the analysis and maintenance of all meteorological and GPS data on the Zeppelin.

P. Zieger was supported by a fellowship of the Swiss National Science Foundation (grant no. P300P2_147776). M. Gysel was supported by the ERC under grant 615922-BLACARAT.

Edited by: F. Pope

\section{References}

Andreae, M. O. and Rosenfeld, D.: Aerosol-cloudprecipitation interactions, Part 1. The nature and sources of cloud-active aerosols, Earth-Sci. Rev., 89, 13-41, doi:10.1016/j.earscirev.2008.03.001, 2008.

Bohren, C. F. and Huffman, D. R.: Absorption and Scattering of Light by Small Particles, Wiley-VCH Verlag GmbH, 530, 2007.

Després, V. R., Huffman, J. A., Burrows, S. M., Hoose, C., Safatov, A. S., Buryak, G., Fröhlich-Nowoisky, J., Elbert, W., Andreae, M. O., Pöschl, U., and Jaenicke, R.: Primary biological aerosol particles in the atmosphere: a review, Tellus B, 64, 15598, doi:10.3402/tellusb.v64i0.15598, 2012.

Ebert, M., Weinbruch, S., Rausch, A., Gorzawski, G., Helas, G., Hoffmann, P., and Wex, H.: Complex refractive index of aerosols during LACE 2010; as derived from the analysis of individual particles, J. Geophys. Res.-Atmos., 107, 8121, doi:10.1029/2000JD000195, 2002.

Fierz-Schmidhauser, R., Zieger, P., Wehrle, G., Jefferson, A., Ogren, J. A., Baltensperger, U., and Weingartner, E.: Measurement of relative humidity dependent light scattering of aerosols, Atmos. Meas. Tech., 3, 39-50, doi:10.5194/amt-3-392010, 2010.

Flores, J. M., Trainic, M., Borrmann, S., and Rudich, Y.: Effective broadband refractive index retrieval by a white light optical particle counter, Phys. Chem. Chem. Phys., 11, 7943-7950, 2009.

Gaigalas, A. K., Wang, L., and Choquette, S.: Measurement of scattering and absorption cross sections of microspheres for wavelengths between $240 \mathrm{~nm}$ and $800 \mathrm{~nm}$, J. Res. Natl. Inst. Stan., 118, 1-14, 2013.

Gysel, M., Weingartner, E., Nyeki, S., Paulsen, D., Baltensperger, U., Galambos, I., and Kiss, G.: Hygroscopic properties of water-soluble matter and humic-like organics in atmospheric fine aerosol, Atmos. Chem. Phys., 4, 35-50, doi:10.5194/acp-4-35-2004, 2004.

Gysel, M., McFiggans, G.B., and Coe, H.: Inversion of tandem differential mobility analyser (TDMA) measurements, J. Aerosol Sci., 2, 134-151, 2009.

Hand, J. L. and Kreidenweis, S. M.: A new method for retrieving particle refractive index and effective density from aerosol size distribution data, Aerosol Sci. Tech., 10, 1012-1026, doi:10.1080/02786820290092276, 2002.

Heim, M., Mullins, B. J., Umhauer, H., and Kasper, G.: Performance evaluation of three optical particle counters with an efficient "multimodal" calibration method, J. Aerosol Sci., 12, 1019-1031, 2008.

Herich, H., Tritscher, T., Wiacek, A., Gysel, M., Weingartner, E., Lohmann, U., Baltensperger, U., and Cziczo, D. J.: Water uptake of clay and desert dust aerosol particles at sub- and super- 
saturated water vapor conditions, Phys. Chem. Chem. Phys., 11, 7804-7809, doi:10.1039/b901585j, 2009.

Kasarova, S. N., Sultanova, N. G., Ivanov, C. D., and Nikolov, I. D.: Analysis of the dispersion of optical plastic materials, Opt. Mater., 29, 1481-1490, doi:10.1016/j.optmat.2006.07.010, 2007.

Kiselev, A., Wex, H., Stratmann, F., Nadeev, A., and Karpushenko, D.: White-light optical particle spectrometer for in situ measurements of condensational growth of aerosol particles, Appl. Optics, 44, 4693-4701, doi:10.1364/AO.44.004693, 2005.

Liu, B. Y. H., Pui, D. Y. H., Whitby, K. T., Kittelson, D. B., Kousaka, Y., and McKenzie, R. L.: Aerosol mobility chromatograph - new detector for sulfuric - acid aerosols, Atmos. Environ., 12, 99-104, doi:10.1016/0004-6981(78)90192-0, 1978.

Ma, X., Lu, J. Q., Brock, R. S., Jacobs, K. M., Yang, P., and Hu, X.H.: Determination of complex refractive index of polystyrene microspheres from 370 to $1610 \mathrm{~nm}$, Phys. Med. Biol., 48, 4165, doi:10.1088/0031-9155/48/24/013, 2003.

Mahowald, N., Albani, S., Kok, J. F., Engelstaeder, S., Scanza, R., Ward, D. S., and Flanner, M. G.: The size distribution of desert dust aerosols and its impact on the Earth system, Aeolian Research, 15, 53-71, doi:10.1016/j.aeolia.2013.09.002, 2014.

Meyer, N. K., Duplissy, J., Gysel, M., Metzger, A., Dommen, J., Weingartner, E., Alfarra, M. R., Prevot, A. S. H., Fletcher, C., Good, N., McFiggans, G., Jonsson, A. M., Hallquist, M., Baltensperger, U., and Ristovski, Z. D.: Analysis of the hygroscopic and volatile properties of ammonium sulphate seeded and unseeded SOA particles, Atmos. Chem. Phys., 9, 721-732, doi:10.5194/acp-9-721-2009, 2009.

Mie, G.: Beiträge zur Optik trüber Medien, speziell kolloidaler Metallösungen, Annalen der Physik, 3, 377-445, doi:10.1002/andp.19083300302, 1908.

Morgan, W. T., Allan, J. D., Bower, K. N., Esselborn, M., Harris, B., Henzing, J. S., Highwood, E. J., Kiendler-Scharr, A., McMeeking, G. R., Mensah, A. A., Northway, M. J., Osborne, S., Williams, P. I., Krejci, R., and Coe, H.: Enhancement of the aerosol direct radiative effect by semi-volatile aerosol components: airborne measurements in North-Western Europe, Atmos. Chem. Phys., 10, 8151-8171, doi:10.5194/acp-10-8151-2010, 2010.

Petters, M. D. and Kreidenweis, S. M.: A single parameter representation of hygroscopic growth and cloud condensation nucleus activity, Atmos. Chem. Phys., 7, 1961-1971, doi:10.5194/acp-71961-2007, 2007.

Pringle, K. J., Tost, H., Pozzer, A., Pöschl, U., and Lelieveld, J.: Global distribution of the effective aerosol hygroscopicity parameter for $\mathrm{CCN}$ activation, Atmos. Chem. Phys., 10, 52415255, doi:10.5194/acp-10-5241-2010, 2010.

Rose, D., Wehner, B., Ketzel, M., Engler, C., Voigtländer, J., Tuch, T., and Wiedensohler, A.: Atmospheric number size distributions of soot particles and estimation of emission factors, Atmos. Chem. Phys., 6, 1021-1031, doi:10.5194/acp-6-1021-2006, 2006.

Rubach, F.: Ph.D. thesis: Aerosol Processes in the Planetary Boundary Layer: High Resolution Aerosol Mass Spectrometry on a Zeppelin NT Airship, Doktorgrad, Fachbereich Mathematik und Naturwissenschaften, Bergische Universität Wuppertal, 147 pp., 2013.

Sjogren, S., Gysel, M., Weingartner, E., Baltensperger, U., Cubison, M. J., Coe, H., Zardini, A. A., Marcolli, C., Krieger, U. K., and Peter, T.: Hygroscopic growth and water uptake kinetics of two-phase aerosol particles consisting of ammonium sulfate, adipic and humic acid mixtures, J. Aerosol Sci., 38, 157-171, doi:10.1016/j.jaerosci.2006.11.005, 2007.

Sorooshian, A., Hersey, S. P., Brechtel, F. J., Corless, A., Flagan, R. C., and Seinfeld, J. H.: Rapid, size-resolved aerosol hygroscopic growth measurements: differential aerosol sizing and hygroscopicity spectrometer probe (DASH-SP), Aerosol Sci. Tech., 42, 445-464, 2008.

Stock, M., Cheng, Y. F., Birmili, W., Massling, A., Wehner, B., Müller, T., Leinert, S., Kalivitis, N., Mihalopoulos, N., and Wiedensohler, A.: Hygroscopic properties of atmospheric aerosol particles over the Eastern Mediterranean: implications for regional direct radiative forcing under clean and polluted conditions, Atmos. Chem. Phys., 11, 4251-4271, doi:10.5194/acp11-4251-2011, 2011.

Stratmann, F., Kiselev, A., Wurzler, S., Wendisch, M., Heintzenberg, J., Charlson, R. J., Diehl, K., Wex, H., and Schmidt, S.: Laboratory studies and numerical simulations of cloud droplet formation under realistic supersaturation conditions, J. Atmos. Ocean. Tech., 21, 876-887, doi:10.1175/15200426(2004)021<0876:LSANSO>2.0.CO;2, 2004.

Stull, R. B.: An Introduction to Boundary Layer Meteorology, Kluwer Academic Publisher, Vancouver, Canada, 673 pp., 1988.

Swietlicki, E., Hansson, H. C., Hameri, K., Svenningsson, B., Massling, A., McFiggans, G., McMurry, P. H., Petaja, T., Tunved, P., Gysel, M., Topping, D., Weingartner, E., Baltensperger, U., Rissler, J., Wiedensohler, A., and Kulmala, M.: Hygroscopic properties of submicrometer atmospheric aerosol particles measured with H-TDMA instruments in various environments - a review, Tellus B, 60, 432-469, doi:10.1111/j.16000889.2008.00350.x, 2008.

Toon, O. B., Pollack, J. B., and Khare, B. N.: Opticalconstants of several atmospheric aerosol species - ammoniumsulfate, aluminum-oxide, and sodium-chloride, J. Geophys. Res.Oceans, 81, 5733-5748, doi:10.1029/JC081i033p05733, 1976.

Topping, D. O., McFiggans, G. B., and Coe, H.: A curved multicomponent aerosol hygroscopicity model framework: Part 1 - Inorganic compounds, Atmos. Chem. Phys., 5, 1205-1222, doi:10.5194/acp-5-1205-2005, 2005.

Tritscher, T., Juranyi, Z., Martin, M., Chirico, R., Gysel, M., Heringa, M. F., DeCarlo, P. F., Sierau, B., Prevot, A. S. H., Weingartner, E., and Baltensperger, U.: Changes of hygroscopicity and morphology during ageing of diesel soot, Environ. Res. Lett., 6, 034026, doi:10.1088/1748-9326/6/3/034026, 2011.

Wiedensohler, A., Birmili, W., Nowak, A., Sonntag, A., Weinhold, K., Merkel, M., Wehner, B., Tuch, T., Pfeifer, S., Fiebig, M., Fjäraa, A. M., Asmi, E., Sellegri, K., Depuy, R., Venzac, H., Villani, P., Laj, P., Aalto, P., Ogren, J. A., Swietlicki, E., Williams, P., Roldin, P., Quincey, P., Hüglin, C., FierzSchmidhauser, R., Gysel, M., Weingartner, E., Riccobono, F., Santos, S., Grüning, C., Faloon, K., Beddows, D., Harrison, R., Monahan, C., Jennings, S. G., O’Dowd, C. D., Marinoni, A., Horn, H.-G., Keck, L., Jiang, J., Scheckman, J., McMurry, P. H., Deng, Z., Zhao, C. S., Moerman, M., Henzing, B., de Leeuw, G., Löschau, G., and Bastian, S.: Mobility particle size spectrometers: harmonization of technical standards and data structure to facilitate high quality long-term observations of atmospheric par- 
ticle number size distributions, Atmos. Meas. Tech., 5, 657-685, doi:10.5194/amt-5-657-2012, 2012.

Zelenyuk, A., Cai, Y., and Imre, D.: From agglomerates of spheres to irregularly shaped particles: Determination of dynamic shape factors from measurements of mobility and vacuum aerodynamic diameters, Aerosol Sci. Tech., 40, 197-217, doi:10.1080/02786820500529406, 2006.

Zieger, P., Weingartner, E., Henzing, J., Moerman, M., de Leeuw, G., Mikkilä, J., Ehn, M., Petäjä, T., Clémer, K., van Roozendael, M., Yilmaz, S., Frieß, U., Irie, H., Wagner, T., Shaiganfar, R., Beirle, S., Apituley, A., Wilson, K., and Baltensperger, U.: Comparison of ambient aerosol extinction coefficients obtained from in-situ, MAX-DOAS and LIDAR measurements at Cabauw, Atmos. Chem. Phys., 11, 2603-2624, doi:10.5194/acp-11-2603-2011, 2011.
Zieger, P., Fierz-Schmidhauser, R., Weingartner, E., and Baltensperger, U.: Effects of relative humidity on aerosol light scattering: results from different European sites, Atmos. Chem. Phys., 13, 10609-10631, doi:10.5194/acp-13-10609-2013, 2013. 